to know your business as well as you do, and without your aid I might suggest a remedy which you will tell me would be worse than the disease. I will venture, however, to mention a possible measure which arises from communications with some practical sheep farmers. The present position, I take it, is that those who have unfortunately got the disease are averse to publicity, as it is likely to make their sheep unsaleable for breeding purposes, and those who have not got it demand, not unfairly, that they shall have some reasonable protection against buying infected stock in the open market. I have been told by farmers who claim to know, but I must take no responsibility for a legal opinion, that if a man sells potentially infective sheep to another the latter has a remedy in common law. Even if that is so, however, I do not see how any sheep farmer could be adequately compensated for the misfortune of having scrapie introduced into his flock.

It has been suggested that with all sheep sold by auction for breeding purposes there should be a guarantee that they have not come from a farm where scrapie exists. It would be open, then, to a farmer who is in doubt, or who has got the disease in his flock, to enter his sheep for sale as slaughter sheep, and I have been informed by one of yourselves that there would be no particularly heavy losses in preparing hoggs for the butcher along with wethers. The practicability from a business point of view of following this plan I must leave to you. I believe, however, that by adopting a measure of this kind a great deal could be done to control the spread of the disease, until science is able to come to the rescue with a practicable method of eradication.

\title{
EXPERIMENTS REGARDING THE VACCINATION OF CATTLE AGAINST TUBERCULOSIS BY THE INTRA- VENOUS INJECTION OF TUBERCLE BACILLI OF THE HUMAN AND AVIAN TYPES.1
}

\author{
(From the Research Institute for Animal Pathology, Royal \\ Veterinary College, London.)
}

By Sir John M'Fadyean, M.R.C.V.S, B.Sc.; A. L. Sheather, M.R.C.V.S., B.Sc. ; J. T. EDWARDS, M.R.C.V.S., B.Sc. ; and F. C. MinetT, M.R.C.V.S., B.Sc.

THE principal purpose of the experiments which are described in this article was to test the effect of intravenous inoculations of tubercle bacilli of the avian type in immunising cattle against bovine tubercle bacilli. Included in the experiments there are also animals which were inoculated intravenously with tubercle bacilli of the human type, but these were employed mainly in order to enable one to compare the immunity or increased resistance which follows vaccination with the two different types.

As is well known, the vaccination of cattle with tubercle bacilli of

\footnotetext{
1 The experiments were carried out by the aid of a grant from the Board of Agriculture and Fisheries. 
the human type was first recommended by von Behring. We do not think it necessary to discuss at any length this method of attempting to immunise cattle against tuberculosis. There is in existence sufficient evidence to show that a very considerable degree of immunity can be conferred in this way on calves, but it also appears to be well established that the immunity is not of a very lasting character. It therefore follows that as a means of combating tuberculosis the vaccination of young cattle with tubercle bacilli of the human type can hardly be expected to have much effect unless the immunity conferred by the first vaccination can be maintained by yearly re-vaccination. Unfortunately the discovery of the fact that after such vaccination the human tubercle bacilli may persist in the body of the vaccinated animal for a long period, and even be passed out with the milk, has made it impossible to consider even a single vaccination with such bacilli as a safe procedure in the case of heifer calves, and has placed an absolute barrier to the re-vaccination of such animals at intervals. It was a consideration of this obstacle to the free use of tubercle bacilli of the human type for vaccinating calves that suggested to us the experiments which we have made with avian tubercle bacilli. It might perhaps be going too far to declare that the avian tubercle bacillus is devoid of pathogenic power for the human subject, but, at anyrate, there is no reason to suppose that that type of bacillus is ever the cause of serious disease in man. From the point of view of apprehended danger to human beings there would therefore be infinitely less objection to the use of avian tubercle bacilli for vaccinating and re-vaccinating cattle.

The following are the only references which we have been able to find regarding the use of avian tubercle bacilli for what may be termed vaccinating purposes:-

Herricourt and Richet ${ }^{1}$ inoculated two monkeys with avian and then with human bacilli, and found that no marked immunity had been conferred against the latter, although the period of the disease was slightly prolonged.

The same authors carried out more numerous experiments with dogs. A dog received two intravenous inoculations of culture of avian tubercle bacilli, viz., one in June and one in October I 89 I (dose not stated). A second dog was inoculated once only in the same way, viz., in October $189 \mathrm{r}$. On the $5^{\text {th }}$ December following this two vaccinated dogs and two controls were inoculated intravenously with I cc. of culture of human tubercle bacilli. The controls died on the 27 th December with "pronounced lesions of tuberculosis," while the two vaccinated dogs were still alive on the 2 Ist March 1892, and had not lost weight. Eight other dogs inoculated intravenously with human tubercle bacilli all died in from fifteen to forty-nine days after the inoculation.

One of the above dogs inoculated with avian bacilli was killed (date not given), and the post-mortem examination showed that it had arthritis of two articulations - a knee and a stifle joint. The lungs contained tuberculous lesions which were in a regressive condition and fibroid in structure.

On the I 4 th April i 892 eight dogs were inoculated with human tubercle bacilli, and four of these had previously received three inoculations of avian tubercle bacilli: The dose given on the r $4^{\text {th }}$ April was I cc. of a forty-five days' culture. The four controls died in eighteen, twenty-one, thirty, and

1 "Compt. Rend. Acad. Sci.," Vol. CXIV., pp. 854 and 1389. 
forty-five days respectively, while the dogs which had been previously inoculated with avian tubercle bacilli survived in perfect health.

On the same day three other dogs which had been inoculated intravenously or intraperitoneally with avian tubercle bacilli were re-inoculated with human tubercle bacilli, and these were also alive and in good health on the 3 rd June following.

In another experiment four dogs were first inoculated with avian tubercle bacilli, and subsequently, along with six control dogs, were inoculated with I cc. of a virulent culture of avian tubercle bacilli modified by successive passages. The four vaccinated animals survived without loss of weight, while of the six controls three died.

Grancher and Martin ${ }^{1}$ inoculated rabbits with cultures of avian tubercle bacilli which were said to have become attenuated by age, but no attempt was made to ascertain whether any immunity was thereby conferred on the animals.

Paterson 2 inoculated rabbits intravenously with avian tubercle bacilli which had been steamed for one and a half hours at $100^{\circ} \mathrm{C}$, and a month later the animals were inoculated into the peritoneum with $\frac{1}{2} \mathrm{cc}$. of a very opaque suspension of virulent mammalian bacilli. The rabbits were killed four and a half months later, and the only lesions discovered were some pedunculated nodules attached to the edge of the liver and to the peritoneum. A second series of rabbits inoculated with dead avian bacilli were subsequently inoculated subcutaneously with virulent mammalian bacilli, and when killed four months later the post-mortem examination showed nothing beyond a caseating lesion at the seat of inoculation. A third series of rabbits which had been inoculated first with dead avian bacilli were afterwards inoculated intravenously with $\frac{1}{3}$ cc. of a suspension of virulent mammalian bacilli. These when killed three months afterwards showed nothing beyond some areas of round-celled infiltration discovered by microscopic examination. A fourth series of rabbiț first inoculated with dead avian bacilli were afterwards inoculated with mammalian bacilli into the anterior chamber of the eye. The result was a tuberculous iritis which disappeared in five weeks.

Although the source of the mammalian bacilli employed by Paterson is not stated it is not improbable that the bacilli were of the human type, in which case the test inoculations made with them were of little or no value for showing whether the rabbits had derived any degree of immunity from the previous inoculation with dead avian bacilli.

In 1898 and $1899 \mathrm{M}^{6} \mathrm{Fadyean}{ }^{3}$ inoculated two cattle with avian tubercle bacilli, and afterwards tested their immunity against bacilli of the bovine type. One of these animals was a heifer about a year old when the experiment was begun in May 1899 . On the 5 th of that month it was tested with tuberculin and did not react. On the roth May it was inoculated intravenously with a rich suspension of tubercle bacilli obtained from the liver of a naturally infected pheasant. When tested with tuberculin twentyone days later the heifer reacted distinctly. On various occasions during the following two years the animal was inoculated intravenously with large doses of mammalian tubercle bacilli. The first test inoculation was with bacilli derived from the liver of a rabbit inoculated intravenously from the tuberculous mesenteric gland of a horse, and later inoculations were with virulent bacilli of the bovine type (derived in one instance from an ox by passage through a rabbit, in another case from a naturally infected sheep by passage through a rabbit, and in the third case directly from a naturally

1 "Rev. de la Tuberculose," Vol. I., 1893, p. 289.

2 "Lancet," 1897 , p. 1106.

3 "Journal of Comparative Pathology and Therapeutics," Vol. XIV., p. 136, and Vol. XV., p. 60; "Transactions of the Pathological Society of London," Vol. LIII., 1902, p. 20. 
infected $\operatorname{dog}$ ). During the year $\mathrm{x} 90 \mathrm{x}$ this heifer received very large doses of artificial culture, the last, which was given on the $24^{\text {th }}$ October, being ro cc. of an emulsion of bacilli from the surface growth of a broth culture. The liquid was so rich in bacilli that it was opaque in a test tube $I$ inch in diameter. The heifer died suddenly on the 23 rd December 1901, the immediate cause of death being tuberculosis of the pia mater, although numerous other tuberculous lesions were found in the body.

The subject of the second case was a cow which was three years old when it was first brought under experiment in September 1898 . On the igth of that month it was tested with tuberculin and there was no reaction. On the 29th September it was inoculated intravenously with an emulsion of tubercle bacilli from the diseased liver of a naturally infected fowl. When tested with tuberculin on the 7 th October following it reacted distinctly. On various dates in 1899,1900 , and 1901 it was inoculated intravenously with mammalian bacilli similar to those employed in the first case. The last inoculation was on the 22 nd January 1902 , and the animal was destroyed when at the point of death on the Ioth February. In this case also the post-mortem examination showed that the animal was the subject of tuberculosis of the pia mater, which had been the cause of the urgent symptoms presented before it was killed. There were also numerous other tuberculous lesions in the body.

In the experiments described in this article all the vaccinations and test inoculations have been carried out with weighed doses of bacilli obtained from the surface growth on 5 per cent. glycerinbroth. As will be seen from the record, doses of from 10 to $50 \mathrm{mg}$. of wet avian bacilli were used, but it ought to be noted that all the calves were at least three or four months old at the time when they were first vaccinated. No animal died as the result of the intravenous inoculation of either avian or human bacilli, and in general the calves did not appear to suffer in any way from the vaccination. On one occasion, however, a number of animals coughed frequently for a few days after the second vaccination (both human and avian bacilli). At the same time the respiration was accelerated, and one or two of the animals afterwards fell off sensibly in condition.

Nothing that has occurred in the course of the experiments lends: any support to the view that avian tubercle bacilli inoculated into cattle may assume the characters proper to bacilli of the bovine type. No doubt the inoculated bacilli when arrested in the capillaries in the lungs and other organs provoke the development of minute tubercles, but these either do not become macroscopic or soon disappear. One calf which had been vaccinated on the Ioth August I9I I with $10 \mathrm{mg}$. of avian bacilli, and re-vaccinated with $20 \mathrm{mg}$. of the same on the and November following, died from hæmorrhage after castration on the 3 rd April 1912 , and the post-mortem examination showed no evidence of tuberculosis in any of the organs.

The same strains of avian, human, and bovine bacilli have been used in all the experiments. The avian and human strains havebeen sub-cultured without animal passage for several years, and the bovine strain has been similarly sub-cultured since it was isolated directly from a bovine lung in 1910.

In the first series of experiments the immunity of a number of the animals was tested by the intravenous inoculation of 3 or $4 \mathrm{mg}$. of bovine bacilli, but this proved to be too severe a test, since all the animals promptly died or were killed when at the point of death 
from a dense miliary tuberculosis of the lungs. It may be noted, however, that the animal which survived longest was the one which had been vaccinated with human bacilli.

In the subsequent test inoculations varying doses of bovine bacilli were inoculated subcutaneously, except in two cases (Calves 44 and 47 ), in which, nine months after the subcutaneous test inoculation, the animals were inoculated intravenously with $2 \mathrm{mg}$. each of bovine bacilli. The doses of bovine bacilli inoculated subcutaneously were varied because it was hoped that it might thus be possible to measure the immunity more accurately.

A detailed account of the distribution and severity of the tuberculous lesions found at the post-mortem examination of each animal will be found in the record of the experiments, but for convenience in comparing human and avian bacilli in respect of the immunity which they confer we give below a condensed statement regarding twenty-nine of the vaccinated animals. We have excluded from this list the five animals of Series I. which succumbed to the intravenous test inoculation with bovine bacilli, as the lesions in all these were practically identical and aftord no information regarding the relative immunity of those vaccinated with human and those vaccinated with avian bacilli. For the same reason we have excluded Calves 44 and 47 in Series II., which subsequent to the subcutaneous test inocalation were inoculated intravenously with bovine bacilli.

In the list we have arranged the animals in the inverse order of the extent and severity of the lesions produced in them by the test inoculation with bovine bacilli.

Calf 10. roth August 19r1, Io mg. hurnan. I8th April 19r2, $5 \mathrm{mg}$. bovine. Killed 3 rd December r 9 r 2 . Lecal lesion very slight.

Calf 39. $25^{\text {th }}$ November I9 I I, I $5 \mathrm{mg}$. human. I 9 th January 1912, 25 mg. human. I8th April 1912, 10 mg. bovine. Killed $24^{\text {th }}$ July 19i2. Local lesion slight.

Calf 54. $25^{\text {th }}$ November 19 II, $20 \mathrm{mg}$. avian. Igth January. 1912, 50 mg. avian. I8th April r912, ro mg. bovine. Killed 25th July 1912. Local Tesion moderate.

Calf $37.25^{\text {th }}$ November I9I I, 10 mg. human. I 9 th January I9I 2, 20 mg. human. 18 th April I9I2, 5 mg. bovine. Killed $3^{\text {th }}$ December Igr 2. Local lesion fibrous only. Prescapular gland slightly diseased.

Calf 62. 2oth February r913, 10 mg. human. 2 Ist June I9I3, $25 \mathrm{mg}$. bovine. Killed 3 rd December Igr3. Local lesion slight. Prescapular gland slightly diseased.

Calf 42. 25th November 19II, $20 \mathrm{mg}$. human. Igth January I9I2, $3^{\circ}$ mg. human. I8th April 1912, ro mg. bovine. Killed 25th July 19i2. Local lesion moderate. Prescapular gland slightly diseased.

Calf 6r. 2oth February igr3, $10 \mathrm{mg}$. human. 2 ist June 1913, $50 \mathrm{mg}$. bovine. Killed 3 rd December 1913. Local lesion moderate. Prescapular gland moderately diseased. One tracheal gland affected.

Calf $3^{8}$. $25^{\text {th }}$ November 191.1, 10 mg. human. I9th January I9I2, 20 mg. human. zoth July i912,20 mg. bovine. Killed and November I9I2. Moderate local lesion. Prescapular gland slightly diseased. Prepectoral glands moderately affected. Cæcal gland one tubercle.

Calf $4 \mathrm{i}$. $25^{\text {th }}$ November I9 1 , I $5 \mathrm{mg}$. human. I 9 th January I 9 I 2,25 mg. human. 2oth July I 9 I $2,40 \mathrm{mg}$. bovine. Killed I 3 th December I 9 I 2. 
Local lesion moderate. Prescapular gland extensively diseased. Intrathoracic glands slightly affected. Mesenteric glands very slightly affected.

Calf 63 . 2oth February 19 3 , $10 \mathrm{mg}$. human. 21st June 1913, $50 \mathrm{mg}$. bovine. Killed 3 rd December 1913. Local lesion moderate. Prescapular gland extensively diseased. Mediastinal, prepectoral, and pharyngeal glands slightly affected.

Calf 6 . roth August 19ri, ro mg. human. 9th February rgr2, $5 \mathrm{mg}$. bovine. Killed 22 nd July r9r2. Local lesion fibrous only. Prescapular gland moderately diseased. Pleura and thoracic glands slightly. Peritoneum slightly affected.

Calf 73. 2oth February I9r3, Io mg. avian. 2ist June 19i3, $50 \mathrm{mg}$. bovine. Killed $5^{\text {th }}$ December I9r3. Local lesion fibrous only. Prescapular gland moderately diseased. Visceral and parietal pleura slightly affected.

Calf 72. 2oth February r9i3, Io mg. avian. 2 ist June I913, $25 \mathrm{mg}$. bovine. Killed $5^{\text {th }}$ December 1913 . Local lesion slight. Prescapular gland extensively involved. Visceral and parietal pleura slightly diseased. One thoracic gland very slightly affected.

Calf 64. 2oth February I913, 10 mg. human. 2ist June 1913, $25 \mathrm{mg}$. bovine. Killed 4 th December 1913. Local lesion moderate. Prescapular gland slightly diseased. Visceral and parietal pleura extensively diseased.

Calf 75 . 2oth February 1913, ro mg. avian. 2rst June 1913, $50 \mathrm{mg}$. bovine. Killed 5th December i9r3. Local lesion moderate. Prescapular gland slightly affected. Visceral and parietal pleura and peritoneum extensively affected.

Calf 17 . Ioth August I $9 \mathrm{II}$, ro mg. avian. 2nd November $19 \mathrm{I} 1,30 \mathrm{mg}$. avian. I8th April r $912,5 \mathrm{mg}$. bovine. Killed 3 rd December r9 I2. Local lesion slight. Prescapular gland extensively diseased. Visceral and parietal pleura and peritoneum extensively diseased.

Calf $7 \mathrm{x}$. 2oth February I9I3, ro $\mathrm{mg}$. avian. 2 ist June $19 \mathrm{r} 3,50 \mathrm{mg}$. bovine. Killed 4 th December 1913 . Local lesion fibrous only. Prescapular gland moderately affected. Thoracic glands slightly, and visceral and parietal pleura extensively diseased. Visceral and parietal peritoneum extensively affected. Left pharyngeal and right popliteal glands slightly involved.

Calf 65. 2oth February i9r3, ro mg. human. 2 ist June r9i3, $50 \mathrm{mg}$. bovine. Killed 4 th December I9r3. Local lesion fibrous only. Prescapular gland slightly diseased. One bronchial gland slightly diseased. Visceral and parietal pleura extensively diseased. Portal glands slightly affected. Visceral and parietal peritoneum extensively diseased.

Calf 23. roth August r9 I I, I5 mg. avian. 2nd November I9r r, $50 \mathrm{mg}$. avian. I8th April 1912, Io mg. bovine. Killed 24th July I912. Local lesion moderate. Prescapular gland extensively diseased. Thoracic glands slightly affected. Spleen slightly diseased.

Calf 25. Ioth August I9I I, Io mg. avian. 9th February 1912, $5 \mathrm{mg}$. bovine. Killed 23 rd July r9 2 . Local lesion moderate. Prescapular gland moderately diseased. Thoracic glands moderately affected. Peritoneum, portal glands, mesenteric glands, and spleen slightly affected.

Calf $55.25^{\text {th }}$ November $1911,20 \mathrm{mg}$. avian. I 9 th January 191 2, $50 \mathrm{mg}$. avian. 2oth July I91 2, $5^{\circ} \mathrm{mg}$. bovine. Killed rst November 1912. Local lesion slight. Prescapular gland extensively diseased. Lungs three tubercles. Heart one tubercle. Visceral and parietal pleura and visceral and parietal peritoneum moderately affected.

Calf 48 . $25^{\text {th }}$ November $191 \mathrm{r}, 20 \mathrm{mg}$. avian. I 9 th January $1912,30 \mathrm{mg}$. avian. 2oth July I9 12, $20 \mathrm{mg}$. bovine. Killed Ist November 19r2. Local lesion moderate. . Prescapular gland extensively diseased. Thoracic glands. moderately affected. Lungs a score of tubercles. 
Calf II. Ioth August I9I I, Io mg. avian. 2nd November I9I I, $20 \mathrm{mg}$. avian. 9th February I9I 2, $5 \mathrm{mg}$. bovine. Killed 8th December 1913. Local lesion moderate. Prescapular gland moderately diseased. Each lung a score of tubercles. Thoracic glands slightly diseased. Spleen five tubercles, mesenteric glands one tubercle.

Calf 53. 25th November I9II, $20 \mathrm{mg}$. avian. 39th January I9I2, $4^{\circ}$ mg. avian. 2oth July 19r2, $40 \mathrm{mg}$. bovine. Killed 3 Ist October 1912. Local lesion slight. Prescapular and one prepectoral gland extensively diseased. Each lung forty tubercles. Liver three tubercles.

Calf I8. Joth August I9I I, Io mg. avian. 2nd November ig I I, $30 \mathrm{mg}$. avian. I8th April 191 2, $5 \mathrm{mg}$. bovine. Killed I6th December I9I2.

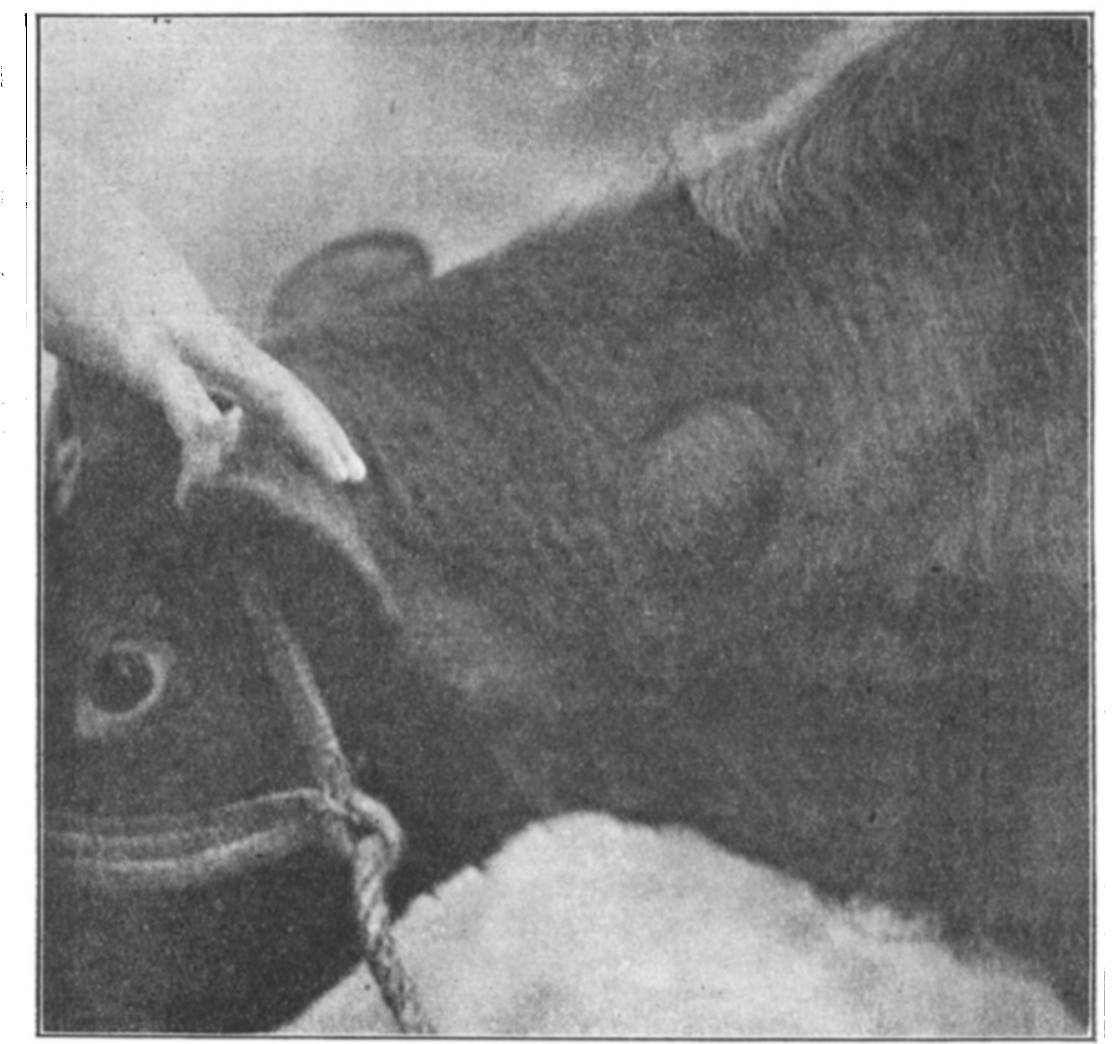

Fig. 1.

Calf 74 (see $\mathrm{p}, 386$ ). The calf, which had been vaccinated with avian bacilli, was inoculated subcutaneously with $25 \mathrm{mg}$. of bovine bacilli on the 21st June 1913. The photograph, which was taken on the 4th September, shows the sharply circumscribed form usually assumed by the local swelling in vaccinated animals.

Local lesion moderate. Prescapular gland moderately diseased. Bronchial and mediastinal glands moderately affected. Left lung three dozen tubercles, right lung one dozen. Pleura moderately diseased. Hepatic glands moderately, mesenteric glands and pharyngeal glands slightly, diseased.

Calf $2 \mathrm{r}$. Ioth August r9I I, ro mg. avian. 2nd November I9I r, $40 \mathrm{mg}$. avian. 2oth July I9r2, $20 \mathrm{mg}$. bovine. Killed i6th December I9 I 2. Local lesion fibrous only. Prescapular gland extensively diseased. Thor- 
acic glands slightly affected. Lungs each about three dozen tubercles. Two tubercles in liver, and one in spleen.

Calf 50 . 25th November I $111,20 \mathrm{mg}$. avian. rgth January 1912,40 mg. avian. I8th April I9I 2, 5 mg. bovine. Killed I6th December I9I2. Local lesion slight. Prescapular gland moderately diseased. Lungs 200 or 3 oo tubercles each. Thoracic glands extensively affected. A score of tubercles in the liver and six in spleen.

Calf 74. 2oth February r9r3, ro mg. avian. 2ist June I9r3, $25 \mathrm{mg}$. bovine. Killed 22 nd October I9I3. Local lesion slight. Prescapular gland extensively involved. Lungs extensively affected, thoracic glands slightly. Mesenteric glands slightly involved.

Calf 19. roth August I9I $10 \mathrm{mg}$. avian. 2nd November I91 1, $40 \mathrm{mg}$. avian. 9th February 19r2, 10 mg. bovine. Killed $23^{\text {rd July I9 } 2 . ~ L o c a l ~}$

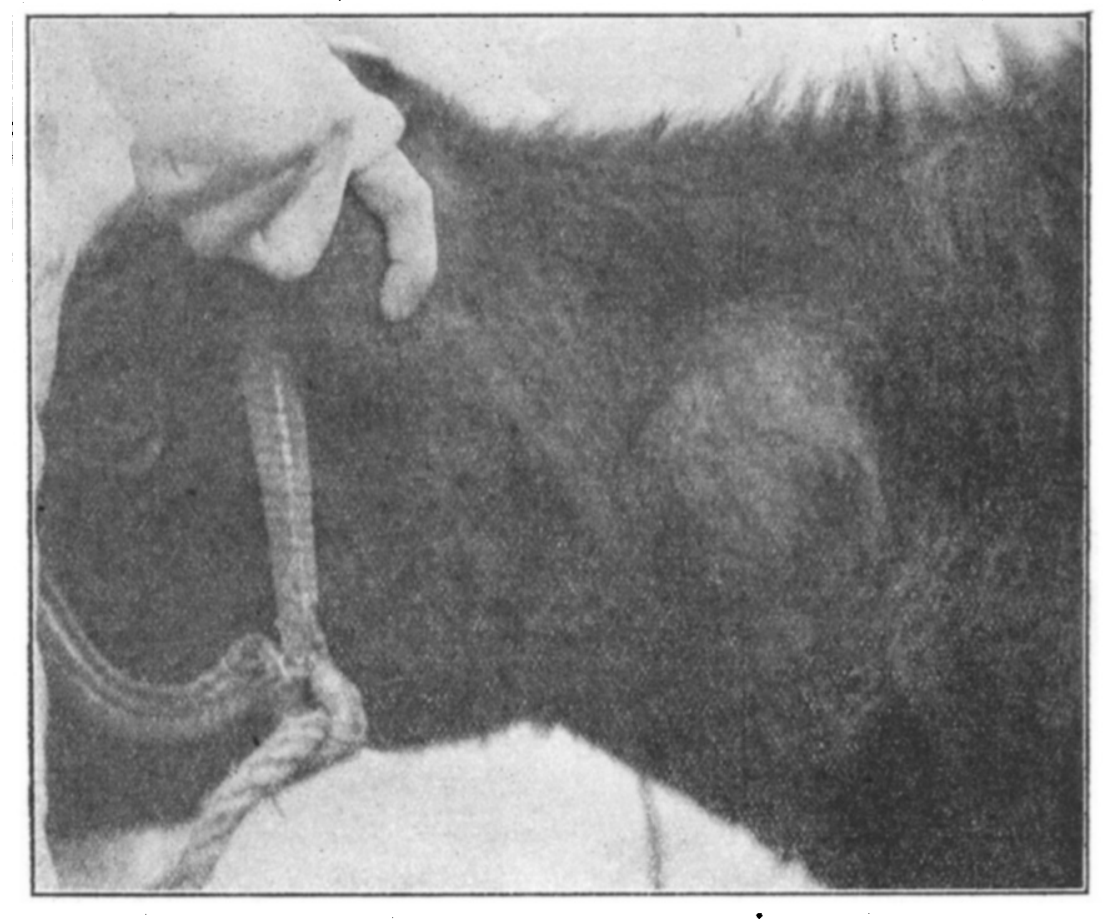

FIG. 2.

Calf 64 (see p. 380). The calf had a similar history to that of the animal shown in fig. 1, except that it had been vaccinated with human bacilli. The photograph was taken on the 4th September.

lesion moderate, prescapular gland extensively diseased. Thoracic glands moderately affected, lungs extensively. Portal glands, spleen, and pharyngeal glands slightly affected.

Even a cursory inspection of the preceding statement shows the superiority of human over avian bacilli in respect of the immunity which follows vaccination, for it will be observed that among the first eleven animals in the series there is only one vaccinated with avian bacilli, and that among the first fifteen there are only four 
vaccinated in that way. With one exception the last fourteen animals in the list were all vaccinated with avian bacilli.

This result is what might have been expected in view of the much closer relationship between the human and the bovine types of bacilli than between the latter and the avian type.

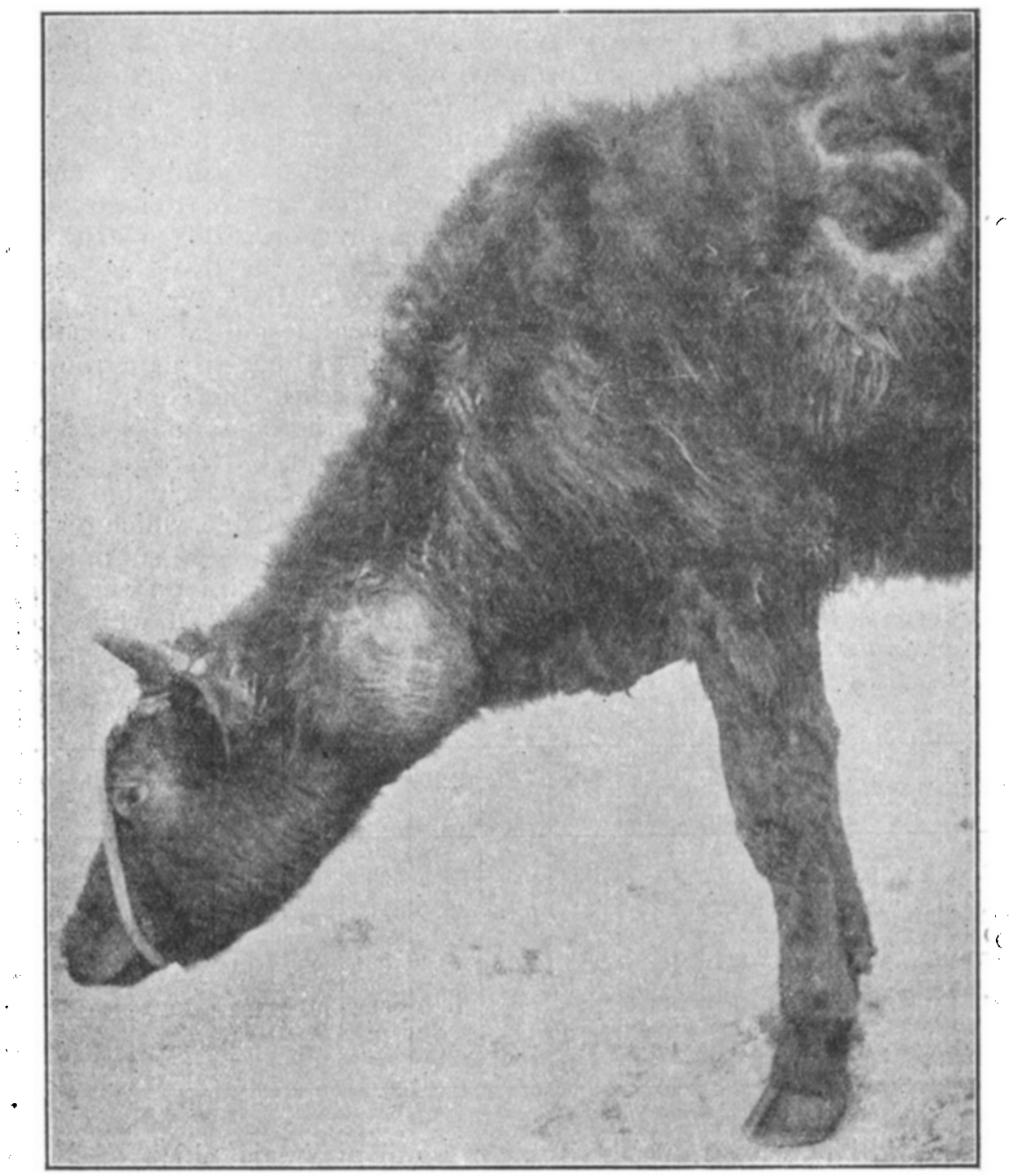

FIG. 3.

Calf 59 (see p. 349). Unvaccinated control animal inoculated subcutaneously with $5 \mathrm{mg}$. of bovine bacilli on the 9th February 1912. Photograph taken on the 26th MIarch following. The fig. shows the extensive diffuse character of the local swelling.

But although the experiments thus show that, putting aside the serious objection already mentioned, human bacilli are superior to avian for vaccinating young cattle, they leave no doubt that as a rule vaccination with avian bacilli greatly increases the resistance to sub- 
sequent infection with bovine bacilli. That conclusion emerges immediately when the results of the test inoculation in the calves thus vaccinated are compared with those which followed in the control animals. And it is of interest to note that there is other evidence than that obtained by comparing the post-mortem records to show that the calves vaccinated with avian bacilli, as well as those vaccinated with human, had acquired an immunity much above that which is natural to young animals of the bovine species. Such evidence was nearly always furnished by the appearance of the local lesion which developed at the seat of inoculation with bovine bacilli, and by the behaviour of the temperature after that inoculation.

At the outset of its formation there was no constant difference between the local swelling in the vaccinated and in the control animals, but after a time there was generally observable a distinct difference in the configuration of the lesion in the two classes of animals, Those differences are exhibited in the accompanying figures. In the vaccinated animals the local lesion soon became more or less sharply delimited and tended to develop as a round projecting "tumour" (see figs. I and 2), whereas in the control subjects the lesion until a much later date, or until the animal's death, persisted as a diffuse swelling with ill-defined margins (see fig. 3).

The varying behaviour of the temperature in the vaccinated and the control animals is illustrated in the following Table, which gives the temperatures for fourteen days of five calves (Series I.) submitted to a subcutaneous test inoculation with bovine bacilli on the 9 th February 19I2. No. 59 was an unvaccinated control calf, while the other four animals had been vaccinated-No. 6 with human, and Nos. I I, I9, and 25 with avian bacilli :-

\begin{tabular}{r|c|c|c|c|c|c|c|c|c|c|c|c|c|c}
\hline No, & $\begin{array}{c}\text { Feb. } \\
12\end{array}$ & $\begin{array}{c}\text { Feb. } \\
13\end{array}$ & $\begin{array}{c}\text { Feb. } \\
14\end{array}$ & $\begin{array}{c}\text { Feb. } \\
15\end{array}$ & $\begin{array}{c}\text { Feb. } \\
16\end{array}$ & $\begin{array}{c}\text { Feb. } \\
17\end{array}$ & $\begin{array}{c}\text { Feb. } \\
18\end{array}$ & $\begin{array}{c}\text { Feb. } \\
19\end{array}$ & $\begin{array}{c}\text { Feb. } \\
20\end{array}$ & $\begin{array}{c}\text { Feb. } \\
21\end{array}$ & $\begin{array}{c}\text { Feb. } \\
22\end{array}$ & $\begin{array}{c}\text { Feb. } \\
23\end{array}$ & $\begin{array}{c}\text { Feb. } \\
24\end{array}$ & $\begin{array}{c}\text { Feb. } \\
25\end{array}$ \\
\hline 59 & $103 \cdot 8$ & 102 & $102 \cdot 4$ & $104 \cdot 2$ & $104 \cdot 4$ & $104 \cdot 4$ & 105 & $105 \cdot 4$ & 105 & $104 \cdot 8$ & 102 & 106 & $105 \cdot 4$ & $106 \cdot 2$ \\
19 & $102 \cdot 6$ & $101 \cdot 4$ & $101 \cdot 4$ & 104 & 105 & $103 \cdot 8$ & $104 \cdot 4$ & 104 & $104 \cdot 8$ & $104 \cdot 4$ & 104 & 104 & $103 \cdot 8$ & 106 \\
6 & 103 & $101 \cdot 6$ & $101 \cdot 8$ & 103 & $101 \cdot 8$ & $101 \cdot 8$ & 102 & $100 \cdot 6$ & $101 \cdot 8$ & 102 & $101 \cdot 8$ & $101 \cdot 4$ & 101 & 103 \\
11 & 102 & $101 \cdot 6$ & $101 \cdot 6$ & $102 \cdot 4$ & $101 \cdot 8$ & $101 \cdot 8$ & $101 \cdot 4$ & $101 \cdot 6$ & $101 \cdot 4$ & $104 \cdot 6$ & $101 \cdot 8$ & $101 \cdot 8$ & $100 \cdot 8$ & $102 \cdot 6$ \\
25 & 101 & $101 \cdot 4$ & $102 \cdot 4$ & $101 \cdot 6$ & $101 \cdot 8$ & $101 \cdot 6$ & $100 \cdot 4$ & 101 & $100 \cdot 4$ & $103 \cdot 2$ & $102 \cdot 8$ & 102 & 101 & $102 \cdot 4$ \\
\hline
\end{tabular}

As will be seen from the Table, the only animals which experienced a serious temperature disturbance were the control calf No. 59 and No. 19. The latter was a vaccinated calf, but it had been inoculated with Io $\mathrm{mg}$ of bovine bacilli, or double the dose given to the other four animals. As might have been expected from the temperature of this animal, the post-mortem examination of No 19 showed that it was one of the worst affected of the vaccinated calves.

Our experiments do not indicate that there is any real advantage in vaccinating a second time after an interval of two or three months either with human or avian bacilli, or that the larger doses of bacilli provoked a stronger immunity than the smaller. 


\section{CONCLUSIONS.}

The conclusions which we feel justified in drawing from our experiments may be formulated thus :-

I. By the intravenous inoculation of avian tubercle bacilli it is possible to confer on healthy calves a markedly increased power of resistance to infection with bacilli of the bovine type.

2. Such a method of vaccinating young cattle against tuberculosis involves little or no risk to the animals.

3. When the vaccination of young cattle against tuberculosis is considered advisable avian bacilli should be preferred to human, in order to avoid the danger of infecting human beings with bacilli persisting in the bodies of the vaccinated animals and passed out with their milk.

\section{RECORD OF EXPERIMENTS.}

\section{SERIES I.}

THIS includes eleven animals which were inoculated with bovine tubercle bacilli on the 9th February 1912. Two of these were healthy calves employed as controls, and of the remaining nine two had been vaccinated (once only) with tubercle bacilli of the human type, while seven had been vaccinated (one once, and six twice) with avian tubercle bacilli, as shown in the accompanying Table.

The bacilli of the human type used for vaccinating Calves 6 and 8 on the Ioth August I9I I were obtained from the surface growth on a glycerin-broth flask which had been incubated since the I Ith July, and the doses mentioned were of the wet bacilli, that is to say, without drying or pressing between filter paper. In all the succeeding vaccinations and test inoculations the bacilli were firmly pressed between several layers of sterile filter paper before they were weighed.

The avian bacilli used for vaccinating the other calves on the same day were similarly taken from a flask which had been incubated since the Igth May.

The avian bacilli used for the second vaccination on the and November I9I I were from the surface growth on a flask which had been incubated since the I 8 th September.

The bovine bacilli used for the test inoculation on the gth February 1912 were from the surface growth on a flask which had been incubated for thirty-one days.

Part of the bovine culture used on the 9 th February for the test inoculations was used on the same date to inoculate one rabbit subcutaneously (dose I mg.), two guinea-pigs subcutaneously (dose - I mg.), and two other guinea-pigs intraperitoneally (dose ${ }^{\prime} \mathrm{I} \mathrm{mg}$.). One of the guinea-pigs inoculated into the peritoneum died from an undiscovered cause on the third day. The other animals all died from tuberculosis - the rabbit on the 22nd April, and the three guinea-pigs on the 6 th, $13^{\text {th }}$, and $14^{\text {th }}$ March respectively.

The calves used in this and the two following series of experiments were Irish animals of a good Shorthorn type (with the exception of the control Calf $44 \mathrm{~A}$, which was a Jersey), and at the time of the 


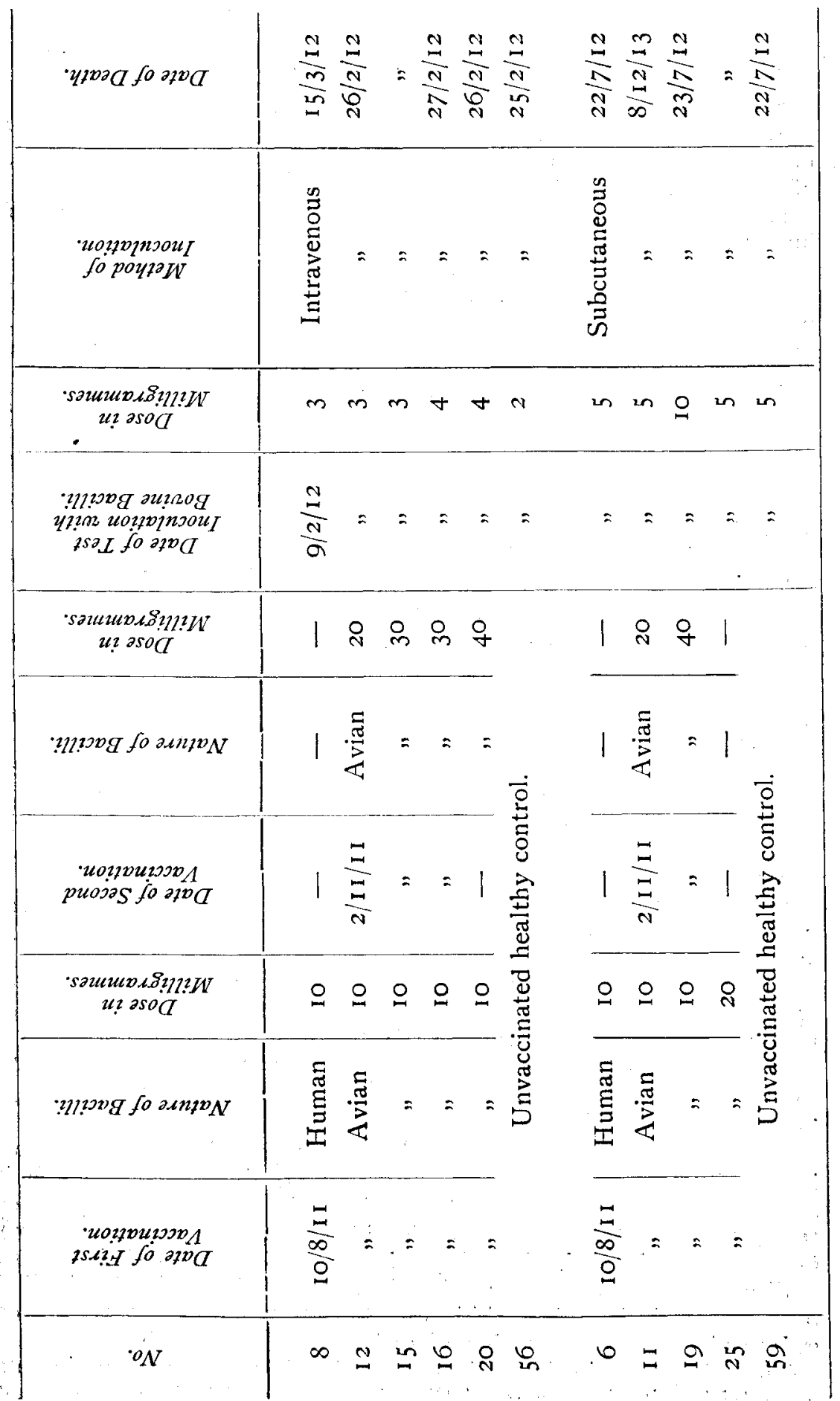


first vaccination they were about four months old and did not vary much in size. The control Calves 56 and 59 were somewhat smaller than the average of the vaccinated animals.

The bull calves were castrated during the course of the experiments, after vaccination, with the exception of No. I I, which was. not castrated until it was two years old.

In the post-mortem record of each animal only the diseased parts are mentioned, but in every case the whole of the thoracic and abdominal organs and lymphatic glands were minutely examined, as. were also the submaxillary, parotid, pharyngeal, prescapular, prepectoral, axillary, precrural, and popliteal groups of glands.

\section{Calf 8 .}

Bull calf. Admitted 28th July I9I I. Tested by the ophthalmic method on the following day, with negative result.

Tested subcutaneously with tuberculin on 4th August. Temperature at the time of injection $103^{\circ} 6^{\circ}$, and maximum temperature during. the following fifteen hours $104^{\circ} 5^{\circ}$, at the twelfth hour.

On the roth August the animal was inoculated intravenously with. Io $\mathrm{mg}$. of culture of tubercle bacilli of the human type. The temperature at the time of inoculation was $103^{\circ} 4^{\circ}$, and the highest temperature recorded during the following fifteen hours was $104^{\circ} 2^{\circ}$, at the sixth and ninth hours.

On the gth February I 9 I 2 it was inoculated intravenously with 3 $\mathrm{mg}$. of a culture of bovine tubercle bacilli. At the time of inoculation the temperature was $1024^{\circ}$, and at the ninth hour it had risen to $105^{\circ} 6^{\circ}$, which was the highest temperature during the fifteen hours following inoculation.

Between the Ioth and I 5 th February the temperature fluctuated between $1034^{\circ}$ and $104^{\circ} 6^{\circ}$. On the I6th February it had fallen to $\mathrm{IO}^{\circ}$, and it remained under $\mathrm{IO}^{\circ}$ afterwards until the Ist March. Between the Ist and I 6 th March the temperature fluctuated between $103.6^{\circ}$ and $104.6^{\circ}$.

After the third week the animal steadily lost condition, and for some time before death the respirations were much increased in frequency. It ceased feeding on the $\mathrm{I} 3^{\text {th }} \mathrm{March}$, and as it appeared to be likely to die soon it was killed on the 15 th March.

The following are the lesions found on post-mortem examination :-

General condition poor.

Lungs. - The apical, second, and third lobes of the right lung, were entirely consolidated, as was also the anterior half of the posterior lobe. The upper posterior part of this lobe was still spongy and somewhat emphysematous. Lesions almost exactly corresponding were present in the left lung. In both lungs discrete white tubercles could be seen through the pleura, especially in the anterior lobes and towards the anterior and lower borders of the posterior lobe. On section innumerable tubercles could be detected in the substance of the lungs, varying in size from ordinary pin's heads down to those just visible to the naked eye.

Thoracic Lymphatic Glands. - The bronchial and mediastinal glands were distinctly enlarged, but on section they presented no distinct caseation and no definite tubercles, although the appearance of the cortical substance of the gland suggested the presence of minute tubercles.

Kidneys. - On stripping the capsule off each kidney about a score of 
discrete tubercles were seen, ranging in size from I $\mathrm{mm}$. downwards, and on cutting into the organs some similar tubercles were discovered both in the cortex and in the medulla.

\section{Calf 12.}

Bull calf. Admitted 28 th July I9I I. Submitted to the ophthalmic tuberculin test on the following day, with negative result.

Tested subcutaneously with tuberculin on the 4 th August. The temperature at the time of injection was $103^{\circ}$, and the highest temperature recorded during the following fifteen hours was $104^{\circ}$, at the ninth hour.

On the Ioth August the animal was inoculated intravenously with Io $\mathrm{mg}$. of culture of avian tubercle bacilli. At the time of inoculation the temperature was $\mathrm{IO}^{\circ}$, and the maximum temperature during the following fifteen hours was $104^{\circ} 2^{\circ}$, at the ninth hour.

On the and November the calf was inoculated intravenously with $20 \mathrm{mg}$. of a culture of avian tubercle bacilli. The temperature at the time of inoculation was $104.5^{\circ}$, and the highest temperature recorded during the following fifteen hours was $100^{\circ} 4^{\circ}$, at the ninth hour.

On the 9 th February $19123 \mathrm{mg}$. of a culture of bovine tubercle bacilli were injected into the jugular vein. The temperature at the time of inoculation was $102.8^{\circ}$, and the highest temperature recorded during the following fifteen hours was $105^{\circ} 6^{\circ}$, at the ninth hour.

Between the 12 th and I 4 th February the temperature varied between $1024^{\circ}$ and $1016^{\circ}$. Between the 15 th and 22 nd February it varied between $102^{\circ}$ and $104^{\circ} 6^{\circ}$ On the 23 rd February it was $107^{\circ}$, and on the following day $106.8^{\circ}$. On the $25^{\text {th }}$ it was $106^{\circ}$, and the animal died the following day. During the last week the respirations had been hurried, and there was rapid loss of condition.

The post-mortem examination revealed the following lesions :-

General condition poor.

Lungs. - More than the half of the lung tissue was solid, and on section it was found to contain innumerable tubercles, mostly of pin-head size, but a few larger.

Thoracic Lymphatic Glands.-The bronchial and mediastinal glands were from two to three times larger than normal. On section they presented an almost uniformly greyish-white appearance, and no definite tubercles could be detected in them.

Liver.-Beneath the capsule and in the parenchyma there were present a few just visible specks (tubercles?).

\section{Calf 15.}

Heifer calf. Admitted 28th July I9II. Submitted to the ophthalmic test on the following day, with negative result.

On the 4th August it was tested subcutaneously with tuberculin. The temperature at the time of injection was $103.3^{\circ}$, and the highest temperature reached during the following fifteen hours was $103.8^{\circ}$, at the ninth and twelfth hours.

On the Ioth August the calf was inoculated intravenously with Io $\mathrm{mg}$. of culture of avian tubercle bacilli. The temperature at time of inoculation was $103.5^{\circ}$, and the highest temperature recorded during the following fifteen hours was $103^{\circ} 6^{\circ}$, at the ninth hour. 
On the 2nd November it was inoculated intravenously with 30 $\mathrm{mg}$. of a culture of avian tubercle bacilli. The temperature at the time of inoculation was $104^{\circ} 1^{\circ}$, and the highest temperature during the following twelve hours was $105^{\circ} 8^{\circ}$, at the sixth hour.

On the 9 th February I 9 I 2 the animal was inoculated intravenously with $3 \mathrm{mg}$. of culture of bovine tubercle bacilli. The temperature at the time of inoculation was $103^{\circ}$, and the highest temperature recorded during the following fifteen hours was $103^{\circ} 6^{\circ}$, at the ninth hour.

From Ioth February up to the 2oth February it never exceeded $103^{\circ} 6^{\circ}$, but on the 2 Ist February it was $104^{\circ} 4^{\circ}$, and on the $23 \mathrm{rd}$ February it had risen to $106^{\circ}$. It was $105^{\circ}$ on the $24^{\text {th }}$ February, and $106^{\circ}$ on the following day. Symptoms as in the preceding case.

The animal died on the 26 th February, and the following are the notes of the post-mortem examination:-

General condition poor.

Lungs.--More than half of the lung tissue was solid, and on section the lung substance was found to be everywhere crammed with just visible tubercles.

Thoracic Lymphatic Glands.- The bronchial and mediastinal lymphatic glands were two or three times the normal size, and on section their substance appeared congested but showed no visible tubercles.

Liver.-Innumerable small tubercles, varying in size from a pin's head downwards, were present under the capsule and in the parenchyma of the organ.

\section{Calf $\mathbf{1} 6$.}

Bull calf. Admitted 28th July I9 I I. Submitted to the ophthalmic tuberculin test on the following day, with negative result.

On the 4th August the animal was tested subcutaneously with tuberculin. The temperature on the previous afternoon was $103^{\circ} 5^{\circ}$, and at the time of injection $103^{\circ}$. The maximum temperature recorded during the following fifteen hours was $104.3^{\circ}$, at the twelfth hour.

On the roth August it was inoculated intravenously with ro $\mathrm{mg}$. of culture of avian tubercle bacilli. The temperature at the time of inoculation was $1045^{\circ}$, and the highest temperature recorded during the following fifteen hours was $104^{\circ} 6^{\circ}$.

On the 2nd November 19I I it was inoculated intravenously with $30 \mathrm{mg}$. of culture of avian tubercle bacilli. The temperature at the time of inoculation was $103^{\circ}$, and the highest temperature recorded during the following fifteen hours was $105^{\circ} 4^{\circ}$, at the ninth hour.

On the 9th February 1912 it was inoculated intravenously with $4 \mathrm{mg}$. of culture of bovine tubercle bacilli. The temperature was $103^{\circ}$ at the time of inoculation, and the highest temperature recorded during the following fifteen hours was $104^{\circ} 6^{\circ}$, at the ninth hour.

Between the 12 th and the 22nd February the temperature varied between $102^{\circ}$ and $104^{\circ} 6^{\circ}$. It had risen to $105^{\circ} 8^{\circ}$ on the $23 \mathrm{rd}$ February, and to $1064^{\circ}$ on the 25 th February. On the following two days it was $105^{\circ} 6^{\circ}$. Symptoms as in the previous cases.

It was killed when in a dying condition on the afternoon of the 
27 th February, and the following are the notes of the post-mortem. examination:-

General condition poor.

Lungs. - Visible through the transparent pleura over the greater part of both lungs there were scattered grey tubercles varying in size from a barley grain to an ordinary pin's head. In the case of the right lung the apical lobe was entirely spongy, and the lobe behind that showed only a few solid lobules. The third lobe was almost entirely solid, and the lower edge of the posterior principal lobe to a vertical height of about 4 inches was also almost entirely hepatised. Almost exactly corresponding areas of hepatisation were present in the left lung, except that there was some consolidation along the lower edge of the apical lobe. Innumerable pin-head tubercles were uniformly present in the lung substance.

Thoracic Lymphatic Glands. - On section the tissue of the bronchial glands was closely beset with opaque dull-white spots and streaks, and the cortical. substance of the mediastinal gland showed a similar appearance.

$$
\text { Calf } 20 \text {. }
$$

Bull calf. Admitted 28th July I9II. On the following day it was submitted to the ophthalmic tuberculin test, with negative result.

On the 4th August it was tested subcutaneously with tuberculin. The temperature on the previous afternoon had been $1027^{\circ}$, and at the time of injection it was $1023^{\circ}$. The maximum temperature recorded during the following fifteen hours was $103^{\circ} 3^{\circ}$, at the sixth hour.

On the Ioth August it was inoculated intravenously with Io mg. of culture of avian tubercle bacilli. At the time of inoculation the temperature was $102^{\circ}$, and the maximum temperature during the following fifteen hours was $1027^{\circ}$, at the ninth and twelfth hours.

On the 2nd November it was inoculated intravenously with 40 mg. of culture of avian tubercle bacilli. The temperature at the time of inoculation was $103^{\circ} 2^{\circ}$, and the maximum temperature during the following twelve hours was $1064^{\circ}$, at the sixth hour.

On the $9^{\text {th }}$ February 1912 the animal was inoculated intravenously with $4 \mathrm{mg}$. of culture of bovine tubercle bacilli. As a result the temperature, which was $102^{\circ}$ at the time of inoculation, rose to $104^{\circ}$ at the ninth hour, and afterwards fell. It remained normal till the 2oth February, when it suddenly rose to $1066^{\circ}$. Two days later it was $108^{\circ}$, and afterwards it did not fall below $106^{\circ}$. Symptoms as in the previous cases.

As the calf appeared to be likely to die soon it was killed on the 26th February, and the post-mortem examination showed the following lesions :-

General condition poor.

Lungs. - Nearly the whole of the apical and middle lobes of the left lung were solid, as was also a small part of the main lobe. Numerous white opaque tubercles could be seen in these parts through the pleura. The area of consolidation in the right lung was almost identical, except that a larger part of the principal lobe was involved. A smaller number of opaque: tubercles were also seen beneath the pleura in the spongy part of each lung. 
On cutting into the lungs it was found that they were everywhere crammed with just visible tubercles.

Thoracic Lymphatic Glands. - The bronchial and mediastinal glands were enlarged to three or four times the normal. There was no recognisable caseation of the gland tissue, but at some places there were indications of definite, very minute tubercles.

Liver.-Beneath the capsule and in the parenchyma there were some just visible points (tubercles?).

\section{Calf 56 (Control).}

Bull calf. Admitted 27th January 19i2. On 29th January it was submitted to the ophthalmic, subcutaneous, and intracutaneous tuberculin tests. The animal's temperature at the time of injection was $103^{\circ}$, and the highest temperature recorded during the following fifteen hours was $104^{\circ}$, at the ninth hour. The ophthalmic and intracutaneous tests also gave negative results.

On the gth February the animal was inoculated intravenously with $2 \mathrm{mg}$. of culture of bovine tubercle bacilli. At the time of inoculation the animal's temperature was $102.2^{\circ}$, and the highest temperature recorded during the following fifteen hours was $\mathrm{IO}^{\circ}$, at the third hour. By the fifteenth hour the temperature had fallen to IOI $8^{\circ}$, and it remained below $102^{\circ}$ for the two days following. On the I 2 th February it rose to $103^{\circ} 2^{\circ}$. From this date it steadily rose to $1066^{\circ}$, which was recorded on the 2 Ist February. The temperature remained at or above $106^{\circ}$ until the $25^{\text {th }}$ February, when the animal died. Hurried respiration and loss of condition, as in the previous cases.

A diffuse swelling about the size of a walnut was observed at the point of penetration of the needle over the jugular vein on the 17 th February.

The following lesions were found at the post-mortem examination :-

General condition poor.

Lungs.-The greater part of the right lung was solid, as was also the anterior half of the left lung. Through the pleura could be seen numerous tubercles, varying in size from a barley grain downwards to those that were scarcely visible. On section the lung tissue was found to be uniformly filled with similar tubercles, the immense majority of which were only just visible.

There were numerous ecchymoses the size of a pin's head under the epicardium, especially along the auriculo-ventricular furrow.

Thoracic Lymphatic Glands.-The bronchial and mediastinal glands were enlarged to three or four times the normal. On section they showed congestion but no definite tubercle formation or caseation. Part of the substance of the glands was streaked and spotted with opaque, white material.

\section{Calf 6.}

Heifer calf. Admitted 28th July I9II. On the following day it was submitted to the ophthalmic tuberculin test, with negative result.

On the $4^{\text {th }}$ August it was tested subcutaneously with tuberculin. The temperature on the previous day was $1034^{\circ}$ in the forenoon and $104^{\circ}$ in the afternoon. At the time of injection the temperature was $103^{\circ} 8^{\circ}$. At the third hour it had risen $14^{\circ}$, after which it steadily fell to $102^{\prime} 9^{\circ}$, at the eighteenth hour. 
On the Ioth August $10 \mathrm{mg}$. of a culture of tubercle bacilli of the human type were injected into the jugular vein. At the time of inoculation the temperature was $102 \cdot 8^{\circ}$, and the highest temperature during the following fifteen hours was $104^{\circ} 5^{\circ}$, at the sixth and ninth hours.

On the 9 th February I9I 2 the animal was inoculated subcutaneously on the left side of the neck with $5 \mathrm{mg}$. of a culture of bovine tubercle bacilli.

The calf's temperature was taken daily from Ioth February till I 8 th April, and during that period it was generally under I0 $3^{\circ}$. It was $104^{\circ}$ on 28 th February, and afterwards, except on the 26 th March when it was tested with tuberculin, it never reached that height.

On the 15 th February there was a swelling at the seat of injection on the calf's neck as large as a hen's egg, and the adjacent prescapular gland was enlarged to nearly that size. A week later the local swelling and the gland were about the same size. On the 29th February the local swelling had not increased in size, but it was tense and painful to the touch. On the Ist March the swelling had burst, and had therefore become reduced in size. On the $4^{\text {th }}$ March it was not larger than a pigeon's egg, and two days later it was reduced to about half that size. On the 8 th March the left prescapular gland felt about the size of a pigeon's egg. On the 2 Ist March the local swelling had increased, and was then about the size of a hen's egg. It burst again two days later, and continued to discharge for some time.

The general condition of the animal did not suffer at any time subsequent to the inoculation with bovine bacilli.

The animal was killed on the 22 nd July 1912, and the following are the notes of the post-mortem examination :-

General condition good.

On the left side of the neck there were two swellings, one at the seat of inoculation and the other caused by enlargement of the prescapular gland. The first of these was smaller than a hen's egg, and at its summit the skin showed some scabby material. On dissection this swelling was found to be composed of connective tissue, in which no caseation or other evidence of tuberculous disease could be detected. The prescapular gland was considerably enlarged, being about $3 \frac{1}{2}$ inches in length by $I$ inch at its thinnest part. On section caseous areas were seen in the substance of the gland.

Thoracic Organs.-The pleura covering the diaphragm showed a good deal of villous-looking tuberculous new growth, and there was a mass of "grapes" on the costal pleura corresponding with the last ribs on the right side of the body. This mass consisted of two or three dozen "grapes" from the size of a small hazel nut downwards.

A few "grapes" were present on the inner surface of the main lobes of each lung. No tubercles could be detected in the substance of the lungs.

The left bronchial gland was somewhat enlarged, and on section it showed a number of separate tubercles, the largest about the size of barley grains. The right bronchial gland was also a little enlarged, and it showed a number of tubercles just visible to the naked eye. The mediastinal gland was slightly increased in size, and a number of yellow tubercles about the size of pin's heads were present in its cortical part.

Abdominal Organs.-On the anterior surface of the liver there were numerous "grapes," the largest having a diameter of about half an inch, 
while the majority were small villous-like outgrowths. There were also a few "grapes" on the posterior surface of the liver.

The peritoneal covering of the spleen showed a considerable amount of diffuse, slightly pinkish, tuberculous growth about the centre of its external surface. On this surface there were also a number of white villous-looking patches, and a great number of these were present on the inner surface of the organ. No tubercles could be detected in the spleen pulp.

There was some tuberculous new growth on the surface of the diaphragm, and there were also some similar patches at the highest part of the loins.

\section{Calf II.}

Bull calf. Admitted 28th July I9I I. Submitted to ophthalmic test on the following day, without reaction.

It was tested subcutaneously with tuberculin on the 4th August. On the preceding day the temperature had been $103^{\circ}$ in the forenoon and $103.5^{\circ}$ in the afternoon. At the time of injection it was $103.3^{\circ}$, and the highest temperature reached during the following fifteen hours was $105^{\circ} 3^{\circ}$, at the ninth hour.

On the Ioth August the animal was inoculated intravenously with Io $\mathrm{mg}$. of avian tubercle bacilli. The temperature at the time of inoculation was $102^{\circ} 6^{\circ}$, and it had risen to $1064^{\circ}$ at the ninth hour, which was the highest temperature reached during the fifteen hours following the operation.

On the and November the calf was inoculated intravenously a second time with avian tubercle bacilli, the dose on this occasion being $20 \mathrm{mg}$. At the time of inoculation the temperature was $103.2^{\circ}$, and the highest temperature during the fifteen hours following was $105^{\circ}$, at the ninth hour.

On the 9 th February 1912 the animal was inoculated subcutaneously on the left side of the neck with $5 \mathrm{mg}$. Of culture of bovine tubercle bacilli. At the time of inoculation the temperature was $103^{\circ}$, and the maximum temperature during the following fifteen hours was $103.6^{\circ}$, at the third hour.

Between the Ioth and the 2oth February the temperature never exceeded $1024^{\circ}$. On the 21 st February it was $104^{\circ} 6^{\circ}$, and between the 22 nd February and the 22 nd March it never exceeded $103^{\circ}$.

By I 4th February there was a swelling at the seat of inoculation as large as a walnut, and by 23 rd February this had increased in size to about that of a hen's egg and was rather diffuse. The adjacent prescapular gland on this date was about the size of a goose's egg. No alterations were observed up till and April. Subsequently this animal's condition always continued good, and both the local swelling and the left prescapular gland gradually diminished in size, although the former did not disappear entirely. It was not castrated till July I9I3, and it was killed in good condition on the 8 th December 1913.

The following lesions were found at the post-mortem examination :-

General condition good.

At the seat of inoculation on the left side of the neck there were three circumscribed swellings, each about $\mathbf{I}$ inch in diameter. These on section were found to have thick fibrous walls and yellow caseo-purulent contents 
which were slightly gritty. The prescapular gland on the same side was not appreciably enlarged, but on section it was found to contain two cavities enclosing yellow caseo-purulent material. The upper cavity was about $\frac{3}{4}$ inch in diameter and the lower $\mathrm{I} \frac{1}{2}$ inches in diameter. The lower appeared to be made up of a number of smaller centres about the size of a bean separated from each other by strands of fibrous tissue.

The left pharyngeal gland contained two tubercles about as large as peas, which on section were found to have thin fibrous capsules and yellow caseous contents which were distinctly gritty.

Thoracic Organs. - The bronchial glands were not appreciably enlarged, but on section were found to be somewhat congested, and each contained six or seven tubercles about the size of peas. On section they were found to consist of a thin fibrous capsule and ycllow caseo-calcareous contents. In some of them there were particles of calcareous matter larger than pin's heads. A gland at the bifurcation of the trachea contained five exactly similar lesions, and two mediastinal glands contained five and nine respectively. Each lung contained about a score of tubercles varying in diameter from $\frac{1}{4}$ to $\frac{1}{2}$ inch. On section these were found to have a thin fibrous wall and yellow caseo-purulent contents which were slightly gritty.

Abdominal Organs.-There were present in the substance of the spleen five tubercles rather smaller than peas. They had thick fibrous capsules with dry caseo-calcareous contents. One of the mesenteric glands contained one tubercle exactly like those found in the spleen.

With regard to this animal it must be observed that it is doubtful whether it was not already infected at the time of purchase. That is made not improbable by the rise of temperature when it was tested subcutaneously with tuberculin on the $4^{\text {th }}$ August I9I I, and by the still more marked temperature reaction to the intravenous injection of ro mg. of avian bacilli six days later. The time which had elapsed between the test inoculation with bovine bacilli and the animal's death made it impossible to determine whether any of the lesions had been the result of natural infection before vaccination.

$$
\text { Calf i9. }
$$

Bull calf. Admitted 28th July I9I I. On the day after admission it was submitted to the ophthalmic tuberculin test, with negative result.

On the $4^{\text {th }}$ August it was tested subcutaneously with tuberculin. The temperature on the afternoon of the previous day had been $103.8^{\circ}$, and at the time of injection it was 102. $8^{\circ}$. The highest temperature recorded during the following fifteen hours was $104^{\circ} 6^{\circ}$, at the sixth hour.

On Ioth August it was inoculated intravenously with $10 \mathrm{mg}$. of culture of avian tubercle bacilli. At the time of injection the temperature was $103^{\circ}$, and during the following fifteen hours the highest temperature recorded was $1044^{\circ}$, at the twelfth hour.

On the 2nd November the animal was inoculated intravenously with $40 \mathrm{mg}$. of culture of avian tubercle bacilli. The animal's temperature at the time of inoculation was $102.8^{\circ}$, and the highest temperature recorded during the following fifteen hours was $106.2^{\circ}$, at the sixth hour.

On the gth February 19 I 2 it was inoculated subcutaneously on the left side of the neck with Io $\mathrm{mg}$. of culture of bovine tubercle bacilli. 
At the time of inoculation the animal's temperature was $102^{\circ}$, and the highest temperature recorded during the following fifteen hours was $104^{\circ}$, at the ninth hour.

From Ioth February till 8 th March the temperature was irregular, fluctuating between $1012^{\circ}$ and $105^{\circ}$, and rising on $25^{\text {th }}$ February to $106^{\circ}$. From 9th March till 22nd March it remained fairly constantly about $\mathrm{IO}^{\circ}$, rising on one occasion only ( $17^{\text {th }}$ March) to $104^{\circ}$. From 23rd March till 18 th April it fluctuated between $\mathrm{IOI}^{\circ} 2^{\circ}$ and $\mathrm{IO}_{4} 2^{\circ}$, but it was more generally near the upper than the lower figure. During this period, viz., on 26th March, the animal was tested with tuberculin, and on the two days following the test the temperature was $105^{\circ}$ and $104^{\circ}$.

On the I 5 th February a swelling about $2 \frac{1}{2}$ inches in its longest diameter had formed at the seat of inoculation, and the adjacent prescapular gland was perhaps a little enlarged.

On the I th February both the local swelling and the gland had considerably increased in size, the latter being now about the size of a hen's egg. On the Igth February the local swelling measured about 5 inches in its long diameter, and the gland was as large as a goose egg and felt nearly confluent with the local swelling. On the following day both the local enlargement and the gland had increased in size, and formed a visible swelling which extended from the point of the shoulder to near the middle of the neck.

On the 2and February the local swelling had become reduced in size, measuring about 4 inches in its longest diameter. The gland remained about the same size as on the 20 th.

On the 26th February there was little alteration except that the gland was somewhat larger. On the 28 th February the local swelling had burst. On the 29 th February the gland felt to be rather smaller than before. On the 8 th March there was little alteration in the size of either the local swelling or the gland, but the former was still discharging. On the I8th March the gland was found to have burst. During the succeeding period the local swelling became a little smaller, as did also the gland.

The animal was killed on the 23 rd July I9I2, and the following lesions were found at the post-mortem examination :-

General condition good.

The swelling at the seat of inoculation in the neck measured about 4 inches in its longest diameter by about 3 inches in its shortest diameter. On pressure a little caseous matter could be made to escape at the point where the swelling had previously discharged. On dissection the enlargement was found to be mainly composed of fibrous material, but in this there were numerous cavities containing soft caseous and slightly gritty material. The left prescapular lymphatic gland was about the same size as the local swelling. A few tubercles were present in the upper part of the gland, while the lower half had been converted into a cavity containing soft caseous and partially calcified material.

Thoracic Organs.-In each lung there were present a score or more of tubercles varying in size from a barley grain to a small pea. These were most numerous in the anterior lobes and along the anterior and lower borders of the main lobes. The centres of these tubercles were caseous and distinctly calcified. Both lungs contained in addition to these larger tubercles a great many minute tuhercles varying in size from a pin's head 
downwards. These smaller tubercles were very firm to the touch and distributed pretty uniformly throughout the tissue of both lungs.

The bronchial glands were not appreciably enlarged, but on section they were found to contain collectively about a dozen discrete yellow tubercles which felt distinctly gritty to the touch. The mediastinal gland, although of normal size, contained a number of similar tubercles.

Abdominal Organs. - The liver parenchyma appeared normal, but the portal glands, although not enlarged, contained a few discrete gritty tubercles about 2 or $3 \mathrm{~mm}$. in diameter. A few tubercles about 2 or $3 \mathrm{~mm}$. in diameter were present in the spleen pulp.

Pharyngeal Lymphatic Glands.-These glands appeared slightly enlarged, but the left was somewhat the smaller of the two. No tubercles were found in the glands on the right side, but about a dozen discrete, caseous, and slightly gritty tubercles were present in the glands of the left side.

$$
\text { Calf } 25 \text {. }
$$

Bull calf. Admitted 28th July I9I I. On the following day it was submitted to the ophthalmic tuberculin test, with negative result.

On the 4th August it was tested subcutaneously with tuberculin. The temperature at the time of inoculation was $103^{\circ}$, and the highest temperature recorded during the following eighteen hours was $103.7^{\circ}$, at the sixth hour.

On the Ioth August it was inoculated intravenously with 20 $\mathrm{mg}$. of culture of avian tubercle bacilli. At the time of inoculation the temperature was $103^{\circ}$, and the highest temperature during the following fifteen hours was $104^{\circ} 8^{\circ}$, at the sixth hour.

On the 9th February I9I2 the animal was inoculated subcutaneously on the left side of the neck with $5 \mathrm{mg}$. of culture of bovine tubercle bacilli. On the day of inoculation with bovine tubercle bacilli the animal's temperature was IOI $4^{\circ}$, and the highest temperature recorded during the following fifteen hours was $103^{\circ}$, at the ninth hour.

From Ioth February until the 25th March it never exceeded $103^{\circ}$. On the 26 th and $27^{\text {th }}$ March it was $104^{\circ}$, and on the 28 th March $1034^{\circ}$; afterwards up to the 6 th April it never reached $103^{\circ}$.

On the I 4 th February a swelling the size of a walnut had formed at the seat of inoculation. On the I6th February the local swelling was about the size of a hen's egg, and the adjacent prescapular gland was felt to be a little enlarged. Up to the 2oth March there was little alteration in the local swelling, but the gland had increased to the size of a goose egg.

The animal was killed on the $23 \mathrm{rd}$ July, and the following lesions were found at the post-mortem examination :-

General condition good.

At the seat of inoculation on the left side of the neck there was a "tumour" about 3 inches in its greatest diameter. On cutting into this it was found to have a thick fibrous wall enclosing greenish-yellow, custard-like material. The prescapular gland on the same side contained two cavities. The larger of these was about $\mathrm{I}$ inch in diameter, and it contained caseous material in an advanced stage of calcification. The smaller contained caseous material which was perceptibly gritty.

Pharyngeal Glands. - These were not enlarged, but on cutting into those on the left side a gritty tubercle about the size of a barley grain was found in 
one of them. The left axillary gland also contained a caseous tubercle in its cortical layer.

Thoracic Organs. - The bronchial glands were closely packed with discrete tubercles about 2 or $3 \mathrm{~mm}$. in diameter.

The mediastinal gland also contained a number of discrete tubercles.

Abdominal Organs. - The hepatic lymphatic glands were not enlarged, but they contained some partially calcified tubercles. No tubercles could be detected in the substance of the liver, but there were some small pin-head elevations of a greyish colour on the surface of the organ.

The spleen showed on both its outer and its inner surface a large number of tuberculous growths, varying in size from a barley grain downwards. A few yellow tubercles about 3 or $4 \mathrm{~mm}$. in diameter were detected in the spleen pulp.

The mesenteric glands were not enlarged, but a few small tubercles were found in some of them. The peritoneum covering the diaphragm and the highest point of the loins carried some yellowish-red tuberculous growths.

\section{Calf 59 (Control).}

Bull calf. Admitted 25th January 1912. The temperature was taken twice daily from the 25 th to the 28 th January, and it was found to vary from $1006^{\circ}$ to $103.6^{\circ}$.

On the 29th January the animal was tested by the subcutaneous, intracutaneous, and ophthalmic methods. The temperature at the time of injection was $1032^{\circ}$, and during the following fifteen hours the highest temperature recorded was $\mathrm{IO}_{3} \cdot 8^{\circ}$, at the sixth hour. The intracutaneous and ophthalmic tests gave negative results.

On the 9th February the animal was inoculated subcutaneously on the left side of the neck with $5 \mathrm{mg}$. of culture of bovine tubercle bacilli. On the day preceding the inoculation the animal's temperature was $104^{\circ} 4^{\circ}$. At the time of inoculation it was $1024^{\circ}$, and during the following fifteen hours the highest temperature recorded was $104^{\circ}$, at the ninth hour.

From the Ioth until the Igth February the animal's temperature slowly rose to $1054^{\circ}$, and from the 20th to the 22 nd February it fell again to $102^{\circ}$. From the 23 rd to the $25^{\text {th }}$ February it varied from $1054^{\circ}$ to $1062^{\circ}$. From the 26 th February until the 2 nd April the temperature varied from $103^{\circ}$ to $1044^{\circ}$, but on 27 th February it was $105^{\circ}$, and on the 26 th March it was $1054^{\circ}$. On the latter occasion the animal was the subject of a tuberculin test. From the 3 rd to the I6th April the temperature did not exceed 102.8 $8^{\circ}$, and on the I 7 th and 18 th April it was $103.2^{\circ}$.

By the 16th February the swelling which had formed at the seat of inoculation on the left side of the neck measured 5 inches in length by 3 inches in width, and on the Igth February it was somewhat altered in shape, measuring 4 inches in each direction. On the 24th February it had increased somewhat in size. On the 7 th March it was found to have burst, but only some watery liquid escaped. On the I Ith March it was found to be about the same size, but it was soft and somewhat tense to the touch (see fig. 3, p. 335). On the 3oth March the swelling again burst, and on pressure about $3 \mathrm{ozs}$. of dirty-white, creamy pus was forced out of it. This caused a reduction in the size of the swelling to about half what it was before.

By the igth February the left prescapular gland had attained the 
size of a goose's egg, and three days later it was about twice that size. On the $24^{\text {th }}$ February it was noted to be as large as a cocoanut, and it remained about that size during the following month.

The animal had fallen off greatly in condition, and it was killed on the 22nd July 19i2. The following lesions were found at the postmortem examination :-

General condition very poor.

At the seat of inoculation there was a swelling measuring 3 inches by $2 \frac{1}{2}$ inches, and on its surface, at the point where it had burst, there was some grape-like outgrowths. On section the greater part of the swelling was found to be composed of fibrous tissue which was closely beset with centres varying in size from a pea to a barley grain. These centres were composed of caseous material which was distinctly gritty. The prescapular gland measured 8 inches by $3 \frac{1}{2}$ inches, and on section was found to have been converted into a cavity with a fairly thick fibrous wall, and filled for the most part with cream-coloured, custard-like material. At the lower part of the cavity there was a quantity of pale pink inspissated material which was very gritty.

Thoracic Organs.-Each lung contained forty or fifty tubercles, varying in size from a pea downwards. The majority of the tubercles were situated in the anterior lobes of the lungs. On section they were composed of caseous material of a pale yellow colour. There were a few small groups of "grapes" on the pleura covering the diaphragm and the chest wall, those on the chest wall being smaller than those on the diaphragm.

Abdominal Organs.-The anterior surface of the liver showed five mushroom like elevations, varying in diameter from $\frac{1}{2}$ to $\mathbf{I}$ inch, and also half-a-dozen smaller lesions of the same kind. The surface of the spleen showed numerous grape-like outgrowths, varying in size from $\frac{1}{2}$ inch in diameter downwards. A single tubercle about 4 or $5 \mathrm{~mm}$. in diameter was found in the substance of the spleen. The parietal peritoneum showed a number of small "grapes," and these were most numerous on the diaphragm, where there were about half-a-dozen clusters, each containing five or six "grapes." There were also present some diffuse patches of tuberculous peritonitis, and similar diffuse lesions were found on the dorsal part of the peritoneum.

One of the uppermost members of the tracheal chain of glands was about the size of a hen's egg, and on section was found to contain a small amount of custard-like material and a large quantity of gritty inspissated matter. One of the prepectoral glands was also enlarged and contained a similar material, but it was distinctly less gritty.

\section{SERIES II.}

As shown in the following Table, this series includes fifteen calves, of which five had been vaccinated with tubercle bacilli of the human type (one once, and four twice), and seven had been twice vaccinated with avian tubercle bacilli. Of the remaining animals two were unvaccinated controls, which, along with the vaccinated animals, were submitted to a test inoculation with bovine tubercle bacilli on the I8th April rgi2. The last calf of the series (44 A) was also unvaccinated, and it was used as a control to a second test inoculation (intravenous) with bovine bacilli to which two of the vaccinated calves (Nos. 44 and 47 ) were submitted. 
GENERAL ARTICLES.

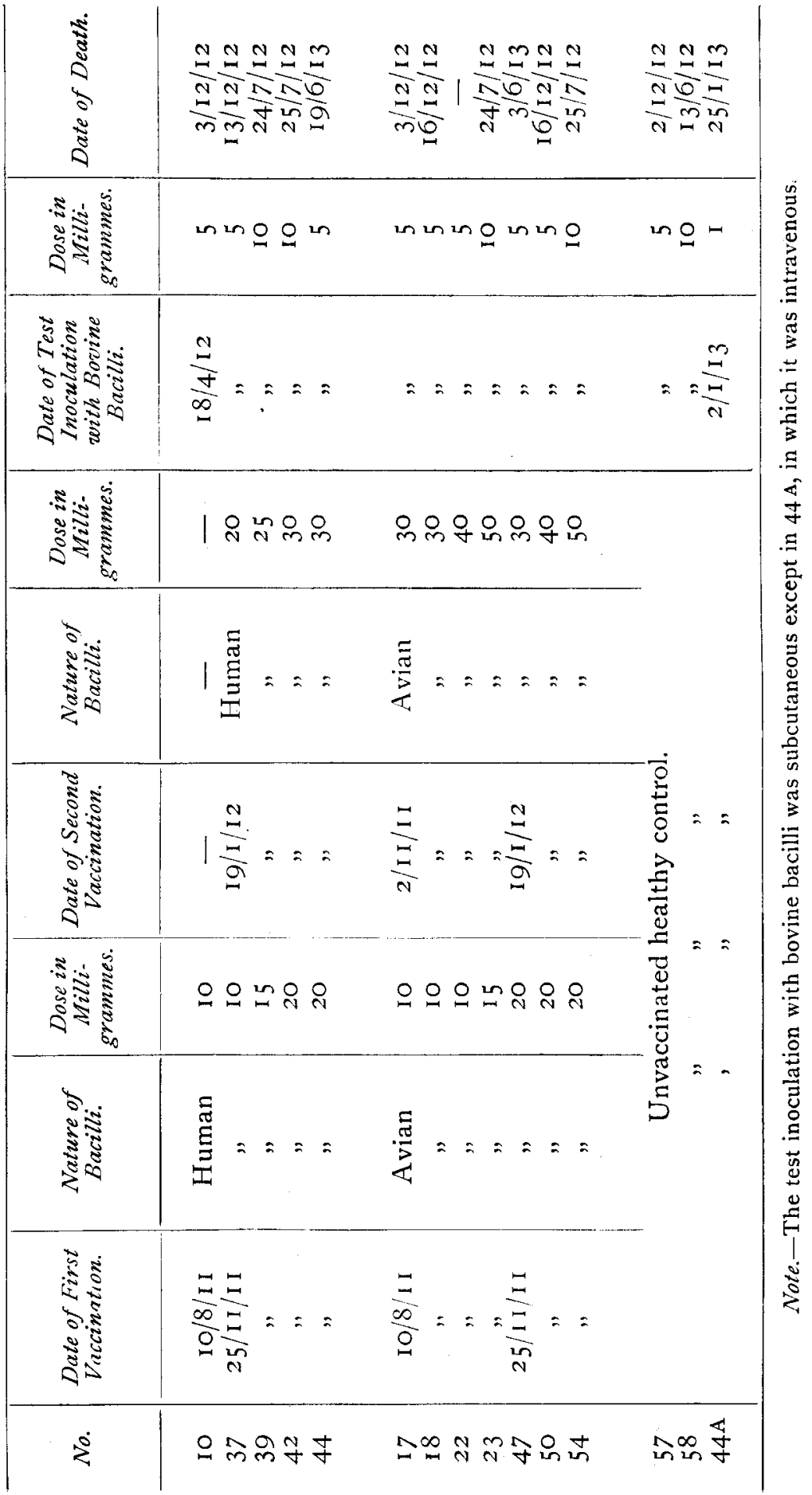


The human tubercle bacilli used for vaccinating No. Io on the Ioth August I9I I were from the same source as those used on that date for animals in Series I. (see p. 337).

The broth cultures which furnished the human bacilli used for vaccination on the 25 th November 19I I and the igth January 19 I 2 had been incubated for eighteen and thirty-five days respectively.

The broth cultures of avian bacilli used on the Ioth August I9I I were the same as that which furnished vaccine on that date for calves in Series I. (see p. 337). The avian culture flasks used on the $25^{\text {th }}$ November I9I I and the I9th January I9I2 had been incubated for twenty-three and twenty-seven days respectively.

The test bovine culture used on the I 8 th April 19 I 2 had been incubated since the 2nd February. This culture was also used on the I8th April to inoculate two rabbits subcutaneously (dose I mg.), two guinea-pigs subcutaneously (dose $1 \mathrm{mg}$ ), and two other guineapigs intraperitoneally (dose $1 \mathrm{mg}$.). One of the rabbits died on the 29th June and the other on the 8th August I912, both tuberculous. The two guinea-pigs inoculated subcutaneously died from tuberculosis on the 23rd May and I 5 th July I9I2, respectively. One of the guinea-pigs inoculated into the peritoneum died on the 2oth May, and the other on the 26 th June r9I 2 , both tuberculous.

The bovine bacilli used on the 2nd January 1913 were from a broth culture which had been incubated since the 2nd November I9II.

\section{Calf Io.}

Bull calf. Admitted 28th July I9I I. Submitted to the ophthalmic tuberculin test on the following day, with negative result.

On the 4th August the animal was tested subcutaneously with tuberculin. The temperature on the previous afternoon had been $1029^{\circ}$, and at the time of injection was $102.5^{\circ}$. The highest temperature recorded during the following fifteen hours was $1043^{\circ}$, at the twelfth hour.

On the Ioth August the animal was inoculated intravenously with ro $\mathrm{mg}$. of culture of human tubercle bacilli. At the time of inoculation the temperature was $102^{\circ} 4^{\circ}$, and the highest temperature recorded during the following fifteen hours was $103.8^{\circ}$, at the ninth hour.

On the I8th April I9I2 the animal was inoculated subcutaneously on the left side of the neck with $5 \mathrm{mg}$. of culture of bovine tubercle bacilli.

On the day following the inoculation the animal's temperature was $102^{\circ}$, and from that day until the $25^{\text {th }}$ May it never rose above IO2. $6^{\circ}$, except on I4th May, when a tuberculin test was carried out. On the 26 th and $27_{\text {th }}$ May it was $103^{\circ}$, after which it fell to $\mathrm{IO}^{\circ}$ or lower, until the $4^{\text {th }}$ June, when there was tuberculin test. Between the 5 th June and the 5 th July it never exceeded $1024^{\circ}$, except on one occasion only, viz., on the 7 th June, when it was $103.6^{\circ}$.

By the 23rd April there had formed at the seat of inoculation at the left side of the neck a circumscribed swelling about the size of a walnut. This local swelling remained about the same size until 
the Ist June, when it had attained the size of a pigeon's egg. The adjacent prescapular gland had increased to about twice the normal size by the I8th May, and it maintained this degree of enlargement until the 22nd June. On the ist July the gland was found to be not appreciably enlarged.

The animal was killed when in good general condition on the 3rd December I9I2, and the following lesions were found at the post-mortem examination :-

At the seat of inoculation there was a small thickening of the skin and subcutaneous tissue, which on section was found to contain a completely calcified centre about the size of a barley grain. The prescapular gland on the same side appeared to be little enlarged, but there was no visible alteration in its structure.

\section{Calf 37 .}

Bull calf. Admitted 3rd November I9I I. On the I4th Novemlier it was submitted to the ophthalmic and intracutaneous tuberculin tests, with negative results.

On the 25 th November it was inoculated intravenously with Io $\mathrm{mg}$. of culture of human tubercle bacilit. At the time of inoculation the temperature was $103^{\circ}$, and the highest temperature during the following fifteen hours was $104^{\circ}$, at the sixth hour.

On the Igth January I9 2 the animal was inoculated intravenously with $20 \mathrm{mg}$. of culture of human tubercle bacilli. At the time of inoculation the temperature was $1012^{\circ}$, and the highest temperature recorded during the following fifteen hours was $1064^{\circ}$, at the sixth hour.

On the I 8 th April I9I 2 the animal was inoculated subcutaneously on the left side of the neck with $5 \mathrm{mg}$. of culture of bovine tubercle bacilli.

On the day after inoculation with bovine tubercle bacilli the animal's temperature was IOI $8^{\circ}$, and up till the 5 th July it was never higher than $1022^{\circ}$, except on four occasions, viz., 26 th and $27^{\text {th }}$ May, when it was $103^{\circ}$, and $14^{\text {th }}$ May and $4^{\text {th }}$ June when the animal was tested with tuberculin.

On the 23 rd April a swelling a little smaller than a walnut had formed at the seat of inoculation. By the 29th April this had decreased somewhat in size, and it remained without further alteration until the $17^{\text {th }} \mathrm{July}$. The adjacent prescapular gland had become enlarged to twice the normal size by the 29th April, and it maintained that size until the I 7 th July.

The animal was killed on the I $3_{\text {th }}$ December I9I2, and the following lesions were found at the post-mortem examination:-

General condition good.

At the seat of inoculation there was a thickening in the skin and subcutaneous connective tissue about $1 \frac{1}{2}$ inches in diameter. On section no caseation or calcification could be seen. In the adjacent prescapular gland there were two tubercles, one about the size of a horse bean and the other rather smaller than a pea. Both were caseo-purulent. 


\section{Calf 39.}

Heifer calf. Admitted 3rd November 19I I. On the 14th November it was submitted to the ophthalmic and intracutaneous tests, with negative results.

On the 25th November it was inoculated intravenously with I $5 \mathrm{mg}$. of culture of human tubercle bacilli. At the time of inoculation the temperature was $102 \cdot 6^{\circ}$, and the highest temperature during the following fifteen hours was $103^{\circ} 8^{\circ}$, at the sixth hour.

On the Igth January 1912 the animal was inoculated intravenously with $25 \mathrm{mg}$. of culture of human tubercle bacilli. At the time of inoculation the temperature was $102^{\circ}$, and during the fifteen hours following the inoculation the highest temperature recorded was $105^{\circ}$, at the twelfth and fifteenth hours.

On the I 8th April the animal was inoculated subcutaneously on the left side of the neck with Io $\mathrm{mg}$, of culture of bovine tubercle bacilli.

On the day after the inoculation with bovine tubercle bacilli the temperature was $102^{\circ}$, and up to the 20 th July it did not rise above 102: $8^{\circ}$, except on 14 th May and 4 th June, when the animal was submitted to tuberculin tests.

By the 27th April a swelling nearly the size of a hen's egg had formed at the seat of inoculation, and after this date it decreased in size. The adjacent prescapular gland had attained a size of about twice the normal by the 6th May, and by the Ist July it was only slightly larger than normal.

The animal was killed on the 24th July I9I2, and the following lesions were found at the post-mortem examination :-

General condition fairly good.

At the seat of inoculation on the left side of the neck there was a circumscribed swelling scarcely larger than a hazel nut. On section this was found to consist of a thick-walled cavity containing a soft but gritty, greenish-yellow material. The prescapular gland on the same side was scarcely enlarged, and on section no tubercles could be discovered in it anywhere.

One hard, calcified white tubercle about the size of a pea was found just under the capsule on the diaphragmatic surface of the liver.

\section{Calf 42.}

Bull calf. Admitted 3rd November I9II. On the I4th November it was submitted to the ophthalmic and intracutaneous tests, with negative results.

On the 25th November it was inoculated intravenously with $20 \mathrm{mg}$. of culture of human tubercle bacilli. At the time of inoculation the temperature was $1034^{\circ}$, and the highest temperature during the following fifteen hours was $104.5^{\circ}$, at the sixth and ninth hours.

On the Igth January I9I 2 it was inoculated intravenously with 30 mg. of culture of human tubercle bacilli. At the time of inoculation the temperature was IOI. $8^{\circ}$, and during the fifteen hours following the inoculation the highest temperature recorded was $105^{\circ} 6^{\circ}$, at the third and sixth hours. 
On the I8th April the animal was inoculated subcutaneously on the left side of the neck with Io $\mathrm{mg}$. of culture of bovine tubercle bacilli.

On the following day the temperature was $104^{\circ}$, and from that date until the 20 th July it did not rise above IO2. $8^{\circ}$, except on I4th May and 4th June, when the animal was tested with tuberculin.

By the 27th April a swelling the size of a walnut had formed at the seat of inoculation, and the swelling maintained this size until Ist June, when it was about the size of a pigeon's egg. By the Ist July the local swelling had increased in size, and measured 6 inches in length by 3 inches in width, and on the 8th July it was found to have burst, discharging creamy pus. The adjacent prescapular gland attained a maximum size of about three times the normal by the I 8 th May, after which it decreased in size.

The animal was killed on the $25^{\text {th }}$ July I9I 2 , and the following lesions were found at the post-mortem examination :-

General condition good.

At the seat of inoculation on the neck there was a swelling measuring about 3 inches in diameter and about $I$ inch in thickness, and the skin covering it showed an orifice through which discharge had passed. On section the swelling was found to be a cavity surrounded by a thick fibrous wall, and containing a greenish-yellow, custard-like material which was gritty to the knife. The prescapular gland on the same side measured about 5 inches in length by $2 \frac{1}{2}$ inches in width, and on section was found to contain in its cortex a number of discrete, yellow, caseous tubercles about 3 or $4 \mathrm{~mm}$. in diameter.

\section{Calf 44 .}

Bull calf. Admitted 3 rd November I9I I. On the 14th November it was submitted to the ophthalmic and intracutaneous tuberculin. tests, without reaction.

On the $25^{\text {th }}$ November it was inoculated intravenously with $20 \mathrm{mg}$. of culture of human tubercle bacilli. At the time of inoculation the temperature was $103^{\circ}$, and the highest temperature reached during the following fifteen hours was $\mathrm{IO}^{\circ} 2^{\circ}$, at the twelfth hour.

On the 19th January I9I 2 the animal was inoculated intravenously with $30 \mathrm{mg}$. of culture of human tubercle bacilli. The temperature at the time of inoculation was IOI: $8^{\circ}$, and during the following fifteen hours the highest temperature recorded was $105^{\circ} 4^{\circ}$, at the twelfth hour.

On the I8th April the animal was inoculated subcutaneously with $5 \mathrm{mg}$. of culture of bovine tubercle bacilli.

On the day after inoculation with bovine tubercle bacilli the animal's temperature was $\mathrm{IOI}^{\circ} 4^{\circ}$, and from this date until the $25^{\mathrm{th}}$ May it never rose above $1024^{\circ}$, except on 14 th May, when a tuberculin test was carried out. On the 26th and 27 th May it was $103^{\circ}$, but from this date onwards until the 2oth July the highest temperature recorded was $102^{\circ} 6^{\circ}$, with the exception of a rise occurring on $4^{\text {th }}$ June as a result of an injection with tuberculin.

By the 27th April a swelling the size of a walnut had formed at the seat of inoculation, and it gradually increased in size until on the Ist July it was about the size of a hen's egg. The adjacent 
prescapular gland showed a maximum increase in size by the 18 th May, when it was about twice the normal size.

On the 2 nd January I 9 I 3 the animal was inoculated intravenously with $2 \mathrm{mg}$. of culture of bovine tubercle bacilli.

On the day following the inoculation the animal's temperature was $1028^{\circ}$, and on the following two days $104^{\circ} 6^{\circ}$. By the 7 th January it had fallen to $1024^{\circ}$. From this date onwards until the 6 th June the temperature remained about normal, with occasional rises to $103^{\circ}$ or a little over.

The animal was killed on the Igth June I9I3, and the following lesions were found at the post-mortem examination :-

General condition moderate.

On the left side of the neck was a circumscribed swelling about $1 \frac{1}{2}$ inches in diameter, and there was another over and above the right carpus. On section the lesion on the side of the neck was found to have a thin fibrous wall surrounding a cavity containing a semi-solid, dirty-white, purulent material. The adjacent prescapular gland was about twice normal size, and on section it was found to contain four caseous centres, each about the size of a walnut.

Thoracic Organs.-Each lung contained about thirty tubercles, varying in size from a horse bean downwards. On section these were found to consist of a thin fibrous wall with caseous contents.

Abdominal Organs. - The liver contained five pea-sized tubercles, which on section showed a very thick fibrous wall and a caseous centre about the size of a millet seed. One similar lesion was found in the spleen. One of the mesenteric glands related to the anterior end of the small intestine was found to contain a caseous tubercle about the size of a horse bean.

About $80 \mathrm{cc}$. of an oily turbid fluid was obtained on opening the knee joint and the sheaths of the extensor tendons. Tubercle bacilli were found in this liquid.

(Compare the results in No. 47 , p. 360 , and in the control calf No. 44A, p. 366$)$.

\section{Calf I 7 .}

Bull calf. Admitted 28 th July I9I I. Submitted to the ophthalmic tuberculin test on the following day, with negative result.

Tested subcutaneously with tuberculin on the $4^{\text {th }}$ August. The temperature on the previous afternoon had been $1034^{\circ}$, and at the time of injection was IO3. $I^{\circ}$. The highest temperature recorded during the following fifteen hours was $\mathrm{IO}_{4} 2^{\circ}$, at the ninth hour.

On the Ioth August the animal was inoculated intravenously with Io mg. of culture of avian tubercle bacilli. The temperature at the time of inoculation was $103^{\circ} \mathrm{I}^{\circ}$, and the highest temperature recorded during the following fifteen hours was $104^{\circ} 5^{\circ}$, at the sixth hour.

On the and November the calf was inoculated intravenously with $30 \mathrm{mg}$. of culture of avian tubercle bacilli. At the time of inoculation the temperature was $102 \cdot 8^{\circ}$, and the highest temperature recorded during the following fifteen hours was $106.2^{\circ}$, at the ninth hour.

On the i8th April 1912 the animal was inoculated subcutaneously on the left side of the neck with $5 \mathrm{mg}$. of culture of bovine tubercle bacilli. 
During the eleven weeks following the inoculation with bovine tubercle bacilli the calf had a temperature varying from $10 \mathrm{I}^{\circ} 2^{\circ}$ to $1034^{\circ}$, except on 3 rd May, when the temperature was $104^{\circ}$, and on I 4th May and 4th June, when the animal was subjected to tuberculin tests.

On the 23rd April a swelling the size of a walnut had formed at the seat of inoculation, and this had increased to the size of a hen's egg on the 27th. By the 29th April the local swelling was of the same size as before, but the adjacent precrural gland was three or four times the normal size. On the Ist May the local swelling showed little alteration, but the gland had increased slightly in size. On the 6th May the local swelling was between 3 and 4 inches in diameter. On the I I th May the local swelling burst, and the gland was about the same size as before. On the I5th May the local swelling had reached the size of a goose egg, but was very circumscribed, and the gland was about six times the normal size. On the Ist June the local swelling was about the same size as before, and the gland was now about four times the normal size. On the 22nd June there was little alteration in the local swelling, and the gland was about the same size or a little larger.

The animal was slaughtered on the 3 rd December 1912, and the following are the notes of the post-mortem examination :-

General condition good.

At the seat of inoculation on the left side of the neck there was a subcutaneous thickening with a surface diameter of about 2 inches and a depth of about $\mathrm{r}$ inch. The bulk of this was composed of dense fibrous tissue, but it contained four separate tubercles, each about 4 or $5 \mathrm{~mm}$. in diameter. The substance of these tubercles was extensively calcified. The prescapular gland on the same side was $13 \mathrm{~cm}$. long by $8 \mathrm{~cm}$. in thickness, and on section it had the appearance of a sac full of yellow caseous material.

Thoracic Organs. - No lesions were found in the thoracic lymphatic glands or lung substance, but there was an extensive tuberculous growth on the parietal and visceral pleura in the shape of flat excrescences.

Abdominal Organs.-Very numerous flat tuberculous excrescences, the largest of which were about $\frac{1}{2}$ inch in diameter, were present on the visceral and parietal peritoneum.

\section{Calf I 8.}

Bull calf. Admitted 28th July I9I I. Submitted to the ophthalmic tuberculin test on the following day, with negative result.

On the 4th August it was tested subcutaneously with tuberculin. The temperature on the previous day had been $104^{\circ}$ in the afternoon, and at the time of injection it was $103.5^{\circ}$. The maximum temperature during the following fifteen hours was $103^{\circ} 6^{\circ}$, at the sixth hour.

On the Ioth August the calf was inoculated intravenously with Io $\mathrm{mg}$. of culture of avian tubercle bacilli. At the time of injection the temperature was $103.2^{\circ}$, and the highest temperature recorded during the following fifteen hours was $105^{\circ} \mathrm{I}^{\circ}$, at the ninth hour.

On the and November the calf was inoculated intravenously with $30 \mathrm{mg}$. of culture of avian tubercle bacilli. At the time of inoculation the temperature was $103.8^{\circ}$, and during the following fifteen hours it rose to a maximum of $1068^{\circ}$, at the sixth hour. 
On the I 8 th April I9I 2 the animal was inoculated subcutaneously on the left side of the neck with $5 \mathrm{mg}$. of bovine culture.

Between the roth April and 4th May the temperature fluctuated between $1014^{\circ}$ and $1022^{\circ}$. On the 5 th May it was $104^{\circ}$, and between the 6th May and 5 th July it never exceeded $103.8^{\circ}$, except on 14 th May and $4^{\text {th }}$ June, when the animal was tested with tuberculin.

On the 23rd April a swelling somewhat smaller than a walnut had formed at the seat of inoculation, and four days later this had not altered in size. At this time the adjacent prescapular gland was little, if at all, enlarged. By the 6th May the gland had increased to two or three times its normal size, but the local swelling was still only about the size of a walnut. On the I 8th May there was little or no alteration in either the local swelling or the gland. On the Ist June the local swelling was about the size of a pigeon's egg and soft on palpation. The gland was then slightly enlarged. There was little or no alteration in the condition of either the local swelling or the gland on the Ist July.

The animal was killed on the 16th December I9I2, and the following are the notes of the post-mortem examination :-

General condition poor.

At the seat of inoculation there was a swelling of about $2 \frac{1}{2}$ inches in diameter, containing at its centre yellow caseous and partly calcified material. The prescapular gland on the same side contained three tuberculous nodules, the largest about the size of a filbert nut.

Thoracic Organs.-On both parietal and visceral pleura there were some flat tuberculous growths, varying in size from a horse bean downwards. The left lung contained about three dozen tubercles about 4 or $5 \mathrm{~mm}$. in diameter. These contained caseous centres. About a dozen similar tubercles were present in the right lung.

The bronchial glands were slightly enlarged, and they contained collectively about a dozen caseous and partly calcified nodules, the largest of which had a diameter of 4 or $5 \mathrm{~mm}$. The mediastinal gland was about three times the normal size, and about twenty similar tubercles were present in its substance.

Abdominal Organs.-No lesions were discoverable in the liver parenchyma, but the hepatic lymphatic glands contained about a dozen caseous and partly calcified tubercles. Eight partially calcified tubercles were found in mesenteric glands.

Pharyngeal Glands.-Three tubercles about 2 to $3 \mathrm{~mm}$. in diameter were found in the left pharyngeal glands, and two of similar size in the right.

$$
\text { Calf } 22 .
$$

Heifer calf. Admitted 28th July I9I I. Submitted to the ophthalmic tuberculin test on the following day, with negative result.

On the 4th August tested subcutaneously with tuberculin. The highest temperature on the previous day had been $103^{\circ} 2^{\circ}$, and at the time of injection it was $1034^{\circ}$. The highest temperature during the following fifteen hours was $104^{\circ}$, at the sixth hour.

On the roth August the animal was inoculated intravenously with Io mg. of culture of avian tubercle bacilli. The temperature at the time of innculation was $103^{\circ}$, and the highest temperature during the following fifteen hours was $1038^{\circ}$, at the fifteenth hour.

On the 2nd November the animal was inoculated intravenously 
with $40 \mathrm{mg}$. of culture of avian tubercle bacilli. The temperature at the time of inoculation was $1034^{\circ}$, and the highest temperature during the following twelve hours, was $1064^{\circ}$, at the ninth hour.

On the I 8 th April 1912 the animal was inoculated subcutaneously on the left side of the neck with $5 \mathrm{mg}$. of culture of bovine tubercle bacilli.

On the day following the inoculation with bovine tubercle bacilli the temperature was $101^{\circ}$, and up till the Ist May it had not exceeded $102^{\circ}$. On the 2 nd May it was $103^{\circ}$, and after that up till the $25^{\text {th }}$ May it never exceeded $\mathrm{IO}_{2}^{\circ}$. Between the 26th May and the 5 th July the highest temperature recorded was $102 \cdot 8^{\circ}$.

On the 29th April a circumscribed swelling about the size of a hen's egg had formed at the seat of inoculation on the calf's neck, and the adjacent prescapular gland felt to be about three or four times the normal in size. On the 6 th May the local swelling was $2 \frac{1}{2}$ inches in diameter, and the swelling corresponding to the gland was 4 inches in diameter. On the IIth May the gland was found to have burst. On the I8th May the local swelling was somewhat smaller and the gland was about six times the normal size. On the Ist June the local swelling was reduced to the size of a pigeon's egg, and the gland had also become distinctly smaller. Up to the Ist July little alteration in the size of either the local swelling or the gland took place, but on that day the local swelling was found to be discharging.

This heifer is still alive and has reared a calf which was born on I6th May I913. At the present time the heifer is in fair condition, and there is only a slight fibrous thickening at the seat of inoculation on the left side of the neck, but the left prescapular lymphatic gland is at least twice the normal size.

\section{Calf 23.}

Bull calf. Admitted 28th July I9I I. Submitted to the ophthalmic tuberculin test on the following day, with negative result.

On the 4th August the calf was tested subcutaneously with tuberculin. At the time of injection the temperature was $102 \cdot 8^{\circ}$, and the highest temperature during the following fifteen hours was $1037^{\circ}$, at the ninth hour.

On the Ioth August it was inoculated intravenously with $15 \mathrm{mg}$. of culture of avian tubercle bacilli. The temperature at the time of inoculation was $102.5^{\circ}$, and the highest temperature recorded during the following fifteen hours was $103^{\circ} 4^{\circ}$, at the ninth hour.

On the and November it was inoculated intravenously with 50 $\mathrm{mg}$. of culture of avian tubercle bacilli. At the time of inoculation the temperature was $1034^{\circ}$, and the highest temperature recorded during the following twelve hours was $105^{\circ} 4^{\circ}$, at the sixth hour.

On the I8th April I9I2 it was inoculated subcutaneously on the left side of the neck with ro $\mathrm{mg}$. of bovine culture.

On the following morning the animal's temperature was $1014^{\circ}$, and up to the 3 oth April it never exceeded $1024^{\circ}$. On the Ist and 2nd May the temperature was $104^{\circ}$, but on the 3 rd May it had fallen to $102 \cdot 6^{\circ}$; and afterwards, up to the 5 th July, the temperature was usually under $102^{\circ}$, except on the $5^{\text {th }}$ May, when it was $103^{\circ}$, and on I $4^{\text {th }}$ May and $4^{\text {th }}$ June, when the animal was tested with tuberculin. 
On the 23rd April a swelling somewhat smaller than a walnut, had formed at the seat of inoculation, and four days later this had increased to the size of a goose egg but was rather sharply circumscribed. On the 29th April the local swelling was unaltered in size, and the adjacent prescapular gland felt three or four times the normal size. On the I Ith May the local swelling had burst. On the I 8th May the gland had increased somewhat in size. There was little alteration in either the local swelling or the gland on the $17^{\text {th }}$ July, but the local swelling continued to discharge at times.

The animal was killed on the 24th July I9I2, and the following lesions were found at the post-mortem examination :-

General condition good,

At the seat of inoculation on the left side of the neck there was a fibrous tumour about 2 inches in diameter. In this were a number of cavities containing greenish-yellow, custard-like material which was distinctly gritty. The largest of these cavities was about the size of a hazel nut.

The prescapular gland on the left side measured 7 by 5 by $3 \frac{1}{2}$ inches. On section the upper portion of the gland was found to contain a large number of caseous centres, the largest about the size of a pea. The lower half of the gland was converted into a thin-walled cavity, from which, on section, there escaped about 2 ozs. of straw-coloured clear liquid, leaving behind a quantity of custard-like distinctly gritty material.

Thoracic Organs.-The bronchial glands were not enlarged, but on cutting into them a few discrete caseous tubercles, about 2 or $3 \mathrm{~mm}$. in diameter, were found. These tubercles were not perceptibly gritty. A few exactly similar tubercles were found in the mediastinal gland.

Abdominal Organs. - The spleen contained a few yellow tubercles similar to those present in the bronchial glands. On the surface of the liver there was a considerable amount of white villous-looking growth.

\section{Calf 47.}

Bull calf. Admitted 3 rd November I9I I. On the 7 th November the animal was submitted to the ophthalmic and intracutaneous tests, without reaction.

On the I $4^{\text {th }}$ November it was tested subcutaneously with tuberculin. At the time of injection the temperature was $103^{\circ}$, and during the following fifteen hours the highest temperature was I03. $5^{\circ}$, at the sixth hour.

On the $25^{\text {th }}$ November the animal was inoculated intravenously with $20 \mathrm{mg}$. of culture of avian tubercle bacilli. At the time of inoculation the temperature was $103.8^{\circ}$, and during the following fifteen hours the highest temperature recorded was $104^{\circ}$, at the twelith hour.

On the Igth January I9I 2 the animal was inoculated intravenously with $30 \mathrm{mg}$. of culture of avian tubercle bacilli. At the time of inoculation the temperature was $102^{\circ}$, and the highest temperature recorded during the following fifteen hours was $1066^{\circ}$, at the sixth hour.

On the I 8 th April the animal was inoculated subcutaneously on the left side of the neck with $5 \mathrm{mg}$. of culture of bovine tubercle bacilli.

On the following day the temperature was $102^{\circ}$, and no temperature above this was recorded until the 5 th and 6 th May, when it rose 
to $103.4^{\circ}$ and $103.6^{\circ}$, respectively. Between the 6th May and 5 th July the temperature rose to $\mathrm{IO}^{\circ}$ on two occasions only, excluding two rises occurring on $4^{\text {th }}$ May and $4^{\text {th }}$ June, when the animal was tested with tuberculin.

By 27 th April a swelling about the size of a walnut had formed at the seat of inoculation, and this remained constant in size until the Ist July, when it was found to have increased in size slightly. The adjacent prescapular gland became enlarged to about four times the normal size by the 6th May, and by the Ist June it had become reduced in size to about twice the normal.

On the 2nd January I9I 3 the animal was inoculated intravenously with $2 \mathrm{mg}$. of culture of bovine tubercle bacilll. At the time of inoculation the temperature was $103.8^{\circ}$, and on the following day it was $1044^{\circ}$. From this date onwards the temperature was normal except for occasional rises to $103^{\circ}$ or a little over.

The animal was killed on the 3 rd June I9I3, and the following lesions were found at the post-mortem examination :-

General condition moderate.

On the left side of the neck, at the seat of inoculation on the 18 th April I 9 I 2 there were three round swellings, each measuring about $1 \frac{1}{4}$ inches in diameter. On section these were found to be thin-walled abscesses containing rather glutinous, greenish-yellow, purulent material. The left prescapular gland was about twice the nornal size, and on section was found to have been converted into a sac full of yellow purulent material.

There was considerable enlargement of the right stifle joint, and about I $20 \mathrm{cc}$. of turbid yellowish liquid was obtained from the joint cavity. This liquid was mucoid in consistency, and after dilution it was centrifuged, but no tubercle bacilli could be found in the deposit.

In the connective tissues immediately above the stifle joint there was a small cavity containing about an ounce of greenish-yellow pus, but the popliteal lymphatic gland appeared to be normal.

Thoracic Organs. - In each lung there was one caseous tubercle about the size of a horse bean, and in the right lung near the base there was an area of hepatisation measuring about $\mathrm{x} \frac{1}{2}$ inches in diameter.

Abdominal Organs.- The spleen contained one tubercle about the size of a horse bean, which on section was found to contain soft caseous material.

The lesions found in this animal should be compared with those in No. 44 (p. 355), which had a similar history, and with those in No. $44 \mathrm{~A}$ (p. 366), which was unvaccinated. It is also of interest to compare the results in Nos. 44 and 47 with those which followed the intravenous inoculation of bovine bacilli in some of the calves of Series I.

It need hardly be said that the second inoculation of Nos. 44 and 47 with bovine bacilli was not intended to test the immunity which had been conferred on them by the vaccination with human bacilli in the one case, and with avian bacilli in the other. Its purpose was to afford some measure of the immunity which had been developed after the first inoculation with bovine bacilli, and the result must be held to show that this later immunity was much stronger than that which usually follows vaccination with either human or avian bacilli. It is, however, impossible to say whether the visceral lesions present at the time of death were attributable to the first or the second inoculation with bovine bacilli. 


\section{Calf 50 .}

Bull calf. Admitted 3rd November 19I I. On the 7 th November it was submitted to the ophthalmic and intracutaneous tuberculin tests, with negative results.

On the I4th November it was subjected to a subcutaneous tuberculin test. The temperature at the time of inoculation was $104^{\circ} 3^{\circ}$, and during the following fifteen hours the highèst temperature recorded was $103^{\circ} 7^{\circ}$, at the ninth hour.

On the $25^{\text {th }}$ November the animal was inoculated with $20 \mathrm{mg}$. of culture of avian tubercle bacilli. On the two days preceding the inoculation the temperature was $105^{\circ}$ and $104^{\circ} 5^{\circ}$, respectively. At the time of inoculation it was $104^{\circ}$, and during the following fifteen hours the highest temperature recorded was 104: $1^{\circ}$, at the sixth hour.

On the 19th January the animal was inoculated intravenously with $40 \mathrm{mg}$. of culture of avian tubercle bacilli. At the time of inoculation the temperature was $1026^{\circ}$, and during the fifteen hours following the injection the highest temperature recorded was $105^{\circ} 4^{\circ}$, at the sixth hour.

On the I8th April the animal was inoculated subcutaneously on the left side of the neck with $5 \mathrm{mg}$. of culture of bovine tubercle bacilli.

On the day after the inoculation the temperature was $102^{\circ}$, and from that date until the $25^{\text {th }}$ May, with the exception of ith May when a tuberculin test was carried out, it rose to $103^{\circ}$ on two occasions only, viz, the 2 Ist April 103.2 $2^{\circ}$, and 5th May $103^{\circ}$. The temperature was $104.8^{\circ}$ on the 26 th May, $1044^{\circ}$ on the $27^{\text {th }}$ May, and $103^{\circ}$ on the 28 th May. On the four days following it varied from $1022^{\circ}$ to $102 \cdot 6^{\circ}$, but it rose again to $104^{\circ}$ on the 2 nd June. From this date up till the 17 th July the temperature was generally under $\mathrm{IO}^{\circ}$, but on the 8 th July it reached $104^{\circ} 2^{\circ}$.

A swelling formed at the seat of inoculation on the left side of the neck, and by the 6th May it had attained a size rather smaller than a hen's egg. On the I 8 th May the swelling was found to have burst. The prescapular gland, which steadily increased in size, attained a maximum of about five times the normal by the Ist July.

The animal was killed on the I6th December I9I2, and the following lesions were found at the post-mortem examination :-

General condition fair.

At the seat of inoculation on the left side of the neck there was a circumscribed swelling about the size of a hen's egg. On section this was found to be composed of fibrous tissue beset with pin-head tubercles with dry caseocalcareous contents. The prescapular gland on the left side was about three times the normal size and it contained a large number of caseo-calcareous. tubercles about 3 or $4 \mathrm{~mm}$. in diameter.

Thoracic Organs. - The bronchial and mediastinal glands were all enlarged to about three or four times the normal. On section they were found to be indurated and closely beset with pin-head tubercles, composed of dry caseocalcareous matter.

Each lung contained from 200 to 300 caseo-calcareous nodules varying in size from a hazel nut downwards.

Abdominal Organs. - The liver contained about a score of tubercles similar 
to those present in the lungs, and the spleen contained six similar lesions. One of the mesenteric glands contained a fibrous nodule about 4 or $5 \mathrm{~mm}$. in diameter, in which no caseous or degenerated centre could be found.

\section{Calf 54 .}

Heifer calf. Admitted 3 rd November I9I I. On the 7 th November the animal was submitted to the ophthalmic and intracutaneous tuberculin tests, with negative results.

On the I $4^{\text {th }}$ November the subcutaneous tuberculin test was carried out. At the time of injection the animal's temperature was $1042^{\circ}$, and the highest temperature recorded during the fifteen hours following was $104^{\circ} 8^{\circ}$, at the sixth hour.

On the $25^{\text {th }}$ November I9I the animal was inoculated intravenously with $20 \mathrm{mg}$. of culture of avian tubercle bacilli. At the time of inoculation the temperature was $102.5^{\circ}$, and the highest temperature recorded during the following fifteen hours was $1047^{\circ}$, at the sixth hour.

On the 19th January the animal was inoculated intravenously with $50 \mathrm{mg}$. of culture of avian tubercle bacilli. At the time of the inoculation the temperature was $1 O I \cdot 3^{\circ}$, and the highest temperature recorded during the fifteen hours following was $1064^{\circ}$, at the fifteenth hour.

On the i 8 th April the animal was inoculated subcutaneously on the left side of the neck with $10 \mathrm{mg}$. of culture of bovine tubercie bacilli.

On the day after the inoculation the temperature was IOI ${ }^{\circ}$. On the $25^{\text {th }}$ April it rose to $103^{\circ} 4^{\circ}$, and on the $25^{\text {th }}$ to $104^{\circ} 6^{\circ}$. With the exception of the I4th May and 4 th June, when tuberculin tests were carried out, the temperature did not rise above $102^{\circ} 2^{\circ}$ from 26 th April to $25^{\text {th }}$ June. On the latter date it was $103^{\circ}$, and afterwards until the 5 th July it rose above $102.4^{\circ}$ on one occasion only, viz., the 3 oth June, when it was $102.8^{\circ}$.

By the $27_{\text {th }}$ April there had formed at the seat of inoculation a swelling about the size of a hen's egg, and this remained constant in size until the Ist June, when it was found to be a little enlarged. The adjacent prescapular gland had attained the size of about three times the normal by the 29 th April, and this increase in size persisted until the Ist June, when the gland was found to be about twice the normal size. Subsequently the gland underwent still further reduction in size.

The animal was killed on the 25 th July I9r2, and the following lesions were found at the post-mortem examination:-

General condition good.

At the seat of inoculation on the left side of the neck there was a spherical swelling measuring about $2 \frac{1}{2}$ inches in diameter, which was somewhat pendulous. At its upper part the swelling was fluctuating and seemed to be on the point of bursting. On section it was found to be composed of a fibrous wall surrounding a yellow custard-like material containing a few gritty particles.

The walls of the cavity were encrusted with gritty material.

The prescapular gland measured about $3 \frac{1}{2}$ inches in length by 2 inches in width, and on section showed no tubercles. 


\section{Calf 57 (Control).}

Bull calf. Admitted 25th January igi2. On the 29th January I 9 I 2 the animal was tested by the subcutaneous, ophthalmic, and intracutaneous methods. The ophthalmic and intracutaneous tests gave negative results. The temperature was taken twice daily for four days preceding the test, and on two occasions registered $104^{\circ}$. At the time of injection the temperature was $1024^{\circ}$, and during the following fifteen hours the highest temperature recorded was $104^{\circ}$ (at the sixth, ninth, and twelfth hours).

On the I 8 th April the animal was inoculated subcutaneously on the left side of the neck with $5 \mathrm{mg}$. of culture of bovine tubercle bacilli.

On the day after inoculation the temperature was IOI' $3^{\circ}$, and from that date until 3 oth April the highest temperature recorded was $\mathrm{IO}_{2} \cdot 8^{\circ}$. On the Ist May the temperature was $104^{\circ}$, and from the and to the $5^{\text {th }}$ it varied from $104^{\circ}$ to $105^{\circ} 2^{\circ}$. Between the 6th May and the 3 rd June it rose to $103^{\circ}$ on three occasions only, viz., I Ith May, 26th May, and 2nd June. On the 5th June the temperature was IO4. $6^{\circ}$, but the animal had been subjected to a tuberculin test on the previous day, and its temperature at the fifteenth hour after injection had been $10 ; \cdot 6^{\circ}$. From the 6 th June until the 20 th July the temperature rose to $103^{\circ}$ or over on three occasions, viz., $25^{\text {th }} \mathrm{June}, 103^{\circ}$; 8th July, $104^{\circ}$; and 9 th $\mathrm{July,} 103^{\circ}$.

At the seat of inoculation on the side of the neck there developed a swelling, which attained the size of a goose egg by the I 8 th May. The adjacent prescapular gland on the same date had attained the size of six times the normal. From this date onwards the local swelling and the prescapular gland both dccreased in size somewhat.

The animal was killed on the 2 nd December I9I2, and the following lesions were found on post-mortem examination:-

General condition good.

At the seat of inoculation on the left side of the neck there was a swelling about the size of a hen's egg. This on section was found to be composed of a fibrous wall with greenish-yellow caseo-purulent contents. The left prescapular gland measured I I cm. in length by $6 \mathrm{~cm}$. in width, and was entirely converted into a yellow caseo-purulent material.

Thoracic Organs.--The bronchial and mediastinal glands were about twice the normal size, and each contained from two to three dozen yellow caseous lesions about the size of split peas.

Each lung contained from $I 5^{\circ}$ to 200 tubercles, varying in size from a horse bean downwards, and composed of yellow caseo-calcareous material.

Abdominal Organs. - The hepatic lymphatic glands were enlarged to about twice the normal size, and each showed two or three dozen yellow caseous tubercles about the size of split peas. The liver contained a dozen circumscribed lesions rather smaller than peas. These on section were found to be composed of a fairly thick capsule with dry yellowish-white gritty contents. The spleen contained about fifty tubercles varying in size from a pea downwards. These on section were found to be composed of caseocalcareous material. Distributed throughout the mesenteric glands there were nine similar tubercles. One such tubercle was found in a cæcal gland and three in the gastric glands.

Other Glands. - The left pharyngeal gland contained one caseo-calcareous tubercle about the size of a vetch pea. A gland close to the trachea about 
the middle of the neck contained a single yellow gritty centre about the size of a pin's head.

The right prescapular gland contained a single caseo-calcareous tubercle the size of a pea. The left and right external iliac glands contained respectively one and two caseo-calcareous tubercles smaller than peas.

\section{Calf 58 (Control).}

Bull calf. Admitted 25th January igi2. The animal's temperature was taken twice daily from the $25^{\text {th }}$ to the 28 th January, and it varied between $104^{\circ} 6^{\circ}$ to $102^{\prime} 2^{\circ}$.

On the 29th January it was subjected to the subcutaneous, ophthalmic, and intracutaneous tests. At the time of injection the temperature was $104^{\circ}$, and the highest temperature recorded during the following fifteen hours was $104 \cdot 8^{\circ}$, at the sixth hour. The intracutaneous and ophthalmic tests gave negative results.

On the I 8 th April the animal was inoculated subcutaneously with Io $\mathrm{mg}$. of culture of bovine tubercle bacilli. On the day following the inoculation the temperature was $102^{\circ}$, and it did not rise above that until the 26 th April, when it was $103^{\circ} 2^{\circ}$. From the 27 th to the 3 oth April it was under $103^{\circ}$. From the Ist May until the I2th June it was constantly varying from $103.6^{\circ}$ to $104^{\circ}$. On the I 3 th June it had fallen to $1024^{\circ}$.

At the seat of inoculation on the left side of the neck there developed a swelling which by the 6th May measured about 3 inches in diameter and was diffuse. The adjacent prescapular gland on this date was three or four times the normal size. By the I 8 th May a second swelling about the size of a walnut had formed, superposed to the first, which still persisted. On the Ist June the local swelling measured 3 inches by $1 \frac{1}{2}$ inches and was diffuse. The prescapular gland on this date was not more than twice the normal size.

The calf lost condition gradually, and it died on the $13^{\text {th }}$ June I9I 2. The following lesions were found at the post-mortem examination:-

Condition very poor.

The local lesion on the side of the neck was found to consist of a cavity containing about 4 ozs. of straw-coloured fluid together with a quantity of inspissated, caseous, yellow, purulent material enclosed by a thin fibrous wall. The adjacent prescapular gland measured 3 inches in length by 2 inches in width. The parenchyma of the gland was of a greyish colour, and it contained a large number of tubercles about the size of pin's heads. These were found to be composed of gritty caseous material.

Thoracic Organs.-Right bronchial glands. There were two glands present-one about the size of a small hen's egg, and the other measuring 4 by 2 by $1 \frac{1}{2}$ inches. On section they were found to have been almost entirely converted into yellowish caseous material, which contained some gritty particles. The left bronchial gland was about the size of a goose egg. and on section was found to be exactly like the right bronchial glands. One of the posterior mediastinal glands was about the size of a small hen's egg, and another measured about 8 inches in length by $I$ inch in thickness. On section these were found to be like the bronchial glands.

The greater part of the right lung was hepatised, and there was a good deal of interstitial emphysema. On section the lung tissue was found to be crowded with caseous tubercles varying in size from a barley grain down to those scarcely visible. The tubercles were rather more numerous in the anterior half of the lung. 
The left lung presented an almost exactly similar appearance.

There were large numbers of ecchymoses under the epicardium, and some caseous tubercles varying in size from a barley grain downwards were found in the walls of the auricles of the heart.

Abdominal Organs.-The hepatic glands were greatly enlarged, the largest of them measuring 3 by 2 inches by 1 inch. On section these glands were found to contain a large amount of gritty caseous matter. No tubercles were discovered in the substance of the liver. The substance of the spleen contained a large number of tubercles about 4 or $5 \mathrm{~mm}$. in diameter. A single longitudinal section showed a score or more of such tubercles. The gastric glands were enlarged, and their cortical portion contained some discrete tubercles.

The mesenteric glands were slightly enlarged, and on section a number of small gritty caseous tubercles were found in the cortical portion of them. The colic glands were enlarged, one being the size of a pigeon's egg. These also contained large numbers of gritty caseous tubercles about the size of a pin's head.

Other Glands.-One of the prepectoral glands was enlarged to about the size of a hen's egg, and on section was found to be almost entirely composed of firm caseous material containing some gritty particles.

The left pharyngeal gland was about $1 \frac{1}{2}$ inches in diameter, and on section showed a group (the size of a pea) of small caseous tubercles. The right pharyngeal gland was rather smaller, and there were a few pin-head tubercles in its cortex. Both submaxillary glands were slightly enlarged, and contained a few pin-head tubercles. The right prescapular gland was not visibly enlarged, but a single tubercle smaller than a pin's head was found in its substance. The iliac glands were slightly enlarged, and contained a number of pin-head tubercles.

$$
\text { Calf } 44 \mathrm{~A} \text { (Control). }
$$

Heifer calf. Born at the College in April I9r2. On the 22nd November I9I 2 it was tested by the subcutaneous, ophthalmic, and intracutaneous methods. At the time of injection the animal's temperature was $102^{\circ}$, and the highest temperature recorded during the following fifteen hours was $103^{\circ} 4^{\circ}$, at the fifteenth hour. The ophthalmic and intracutaneous tests gave negative results.

The animal was inoculated intravenously with I $\mathrm{mg}$. of culture of bovine tubercle bacilli on the 2nd January 1913. On the day of inoculation its temperature was $\mathrm{IO}^{\circ} 3^{\circ}$. From that date until the I Ith January it did not exceed $1024^{\circ}$, save on the 8 th January, when it was $103^{\circ}$. From the 12 th January to the 15 th it steadily rose to a maximum of $107.6^{\circ}$, and from the I6th January until the $24^{\text {th }}$ it varied from $105^{\circ} 6^{\circ}$ to $106^{\circ} 4^{\circ}$.

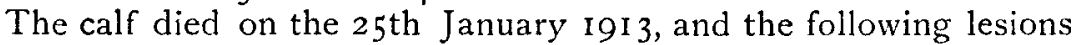
were found at the post-mortem examination :-

\section{Condition poor.}

Thoracic Organs. - The left bronchial gland was about four times the normal size, and on section was found to be closely packed with pin-head tubercles. The right gland was normal in size and contained about twenty similar tubercles. The mediastinal glands were about five times the normal size and were closely beset with pin-head tubercles. The lungs were closely packed with miliary tubercles.

Abdominal Organs.-. Very large numbers of white tubercles about the size of millet seeds were found evenly distributed throughout the parenchyma of the liver. The spleen contained two similar tubercles. In the left kidney two pin-head tubercles were found immediately under the capsule. 
In the right kidney there were two similar lesions immediately under the capsule, and one was found in the parenchyma. One pin-head tubercle was found in the right external iliac gland.

This calf was employed as a control to the intravenous second test inoculation of Nos. 44 and 47 with bovine bacilli (see pp. 356 and 361 ). It is obvious that the results are not strictly comparable, inasmuch as No. $44 \mathrm{~A}$ was a much younger and smaller animal than the other two, but the rapid course of the disease in the former is sufficient evidence of the virulence of the bovine bacilli employed.

\section{SERIES III.}

The eight animals included in this series comprised two which had been twice vaccinated with tubercle bacilli of the human type, and four which had been twice vaccinated with avian tubercle bacilli (see Table). The remaining two animals had not been vaccinated and were used as controls. On the 20 th July 1912 all these animals were submitted to a subcutaneous test inoculation with varying doses of bovine tubercle bacilli from a broth culture which had been incubated for forty days.

The human and avian cultures used as vaccines were the same as those employed on the same dates for animals in Series II.

\section{Calf 38.}

Bull calf. Admitted 3rd November 19I I. On the I4th November it was submitted to the ophthalmic and intracutaneous tuberculin tests, with negative results.

On 25th November it was inoculated intravenously with Io $\mathrm{mg}$. of culture of human tubercle bacilli. At the time of inoculation the animal's temperature was $102^{\circ}$, and the highest temperature during the following fifteen hours was $104^{\circ} 6^{\circ}$, at the sixth hour.

On the I9th January I9I 2 the animal was inoculated intravenously with $20 \mathrm{mg}$. of culture of human tubercle bacilli. At the time of inoculation the temperature was $102^{\circ}$, and during the fifteen hours following it rose to $105^{\circ}$, at the third hour, and after falling to $103^{\circ} 8^{\circ}$ at the sixth hour, it rose again to $105^{\circ} 2^{\circ}$ at the twelfth hour.

On the 2oth July the animal was inoculated subcutaneously on the left side of the neck with $20 \mathrm{mg}$. of culture of bovine tubercle bacilli.

On the day of inoculation with bovine tubercle bacilli the animal's temperature was $103.2^{\circ}$, and there was no elevation of temperature above $103^{\circ}$ during the next three months, save on 14 th August and 25 th and 3oth September, when the animal was tested with tuberculin.

On the 27 th July a swelling measuring 2 inches in diameter and $\frac{3}{4}$ inch in thickness had formed at the seat of inoculation, and the adjacent prescapular gland was about the size of a hen's egg. By the Ioth August the local swelling had decreased until it measured only $\mathrm{I}$ inch in diameter, the prescapular gland remaining about the same size. No alteration in the size of the local swelling was recorded up to the 30 th September I9I 2. 


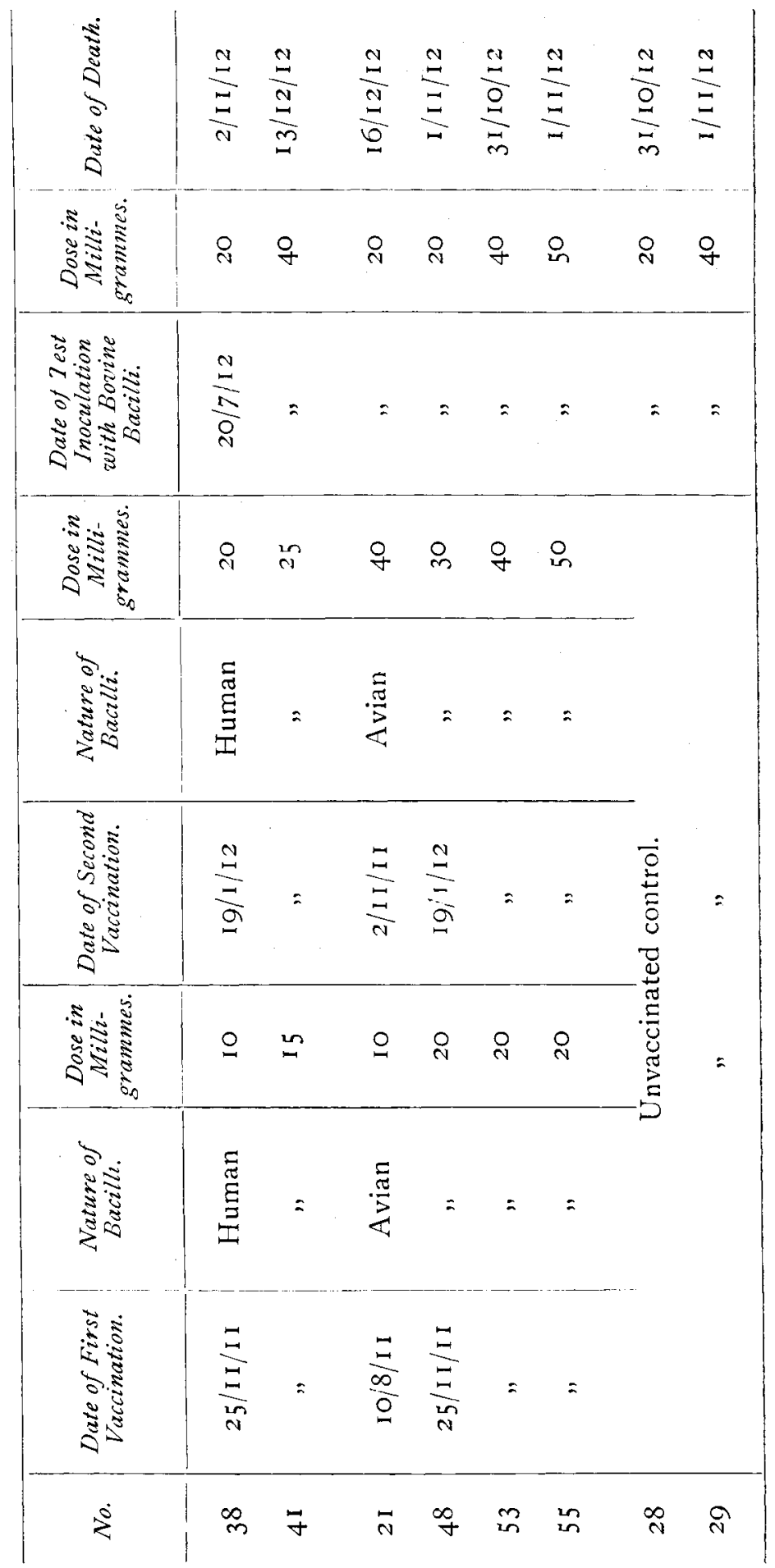


The animal was killed on the 2 nd November 1912, and the following lesions were found at the post-mortem examination:--

General condition very good.

At the seat of inoculation on the left side of the neck there was a firm swelling about the size of a turkey's egg, and on section this was found to consist of a cavity containing greenish-yellow custard-like material, with a few gritty particles in it, surrounded by a fibrous wall about $\frac{1}{1 \bar{B}}$ inch in thickness. The prescapular gland was not sensibly enlarged, and on section it was found to contain one tubercle about the size of a horse bean. This was composed of caseo-purulent matter together with a little clear liquid.

The prepectoral glands on the left side were not enlarged, but they contained a considerable amount of caseo-purulent material.

Abdominal Organs.-On section one of the cæcal glands was found to contain a yellow tubercle about the size of a pin's head.

$$
\text { Calf } 4 \mathrm{I} \text {. }
$$

Bull calf. Admitted 3 rd November 191 I. On I4th November it was submitted to the ophthalmic and intracutaneous tuberculin tests, with negative results.

On $25^{\text {th }}$ November it was inoculated intravenously with I $5 \mathrm{mg}$. of culture of human tubercle bacilli. At the time of inoculation the temperature was $103.6^{\circ}$, and the highest temperature recorded during the following fifteen hours was $105^{\circ}$, at the sixth hour.

On the 19th January I9I 2 the animal was inoculated intravenously with $25 \mathrm{mg}$. of culture of human tubercle bacilli. At the time of inoculation the temperature was $1024^{\circ}$, and during the following fifteen hours the highest temperature recorded was $105^{\circ} 6^{\circ}$, at the ninth and twelfth hours.

On the 2oth July the animal was inoculated subcutaneously on the left side of the neck with $40 \mathrm{mg}$. of culture of bovine tubercle bacilli.

On the day of inoculation with bovine bacilli the animal's temperature was $103^{\circ}$. On the day following it was $1034^{\circ}$, and during the following two months it did not rise above $103^{\circ}$, except on 14 th August and $25^{\text {th }}$ and 30 th September, when the animal was tested with tuberculin.

A swelling formed at the seat of inoculation reached its maximum size by the I 7 th August, measuring 4 inches in length by 2 inches in width. The adjacent prescapular gland on the same date was almost as large as a turkey's egg. By the $24^{\text {th }}$ September the local swelling measured only 3 inches by $\mathrm{I}_{2} \frac{1}{2}$ inches, but it was found to be discharging creamy pus.

The animal was killed on the I3th December I9I2, and the following lesions were found at the post-mortem examination :-

General condition good.

At the seat of inoculation on the left side of the neck there was a circumscribed swelling $2 \frac{1}{2}$ inches in diameter, which on section was found to consist of a cavity containing caseo-purulent material surrounded hy a thick fibrous wall. The prescapular gland on the same side measured $12 \mathrm{~cm}$. by $8 \mathrm{~cm}$., and on section it was found to be entirely converted into caseopurulent material.

Thoracic Organs. - The right and left bronchial glands contained six caseous tubercles rather smaller than peas. The posterior mediastinal gland contained one similar tubercle. A gland at the bifurcation of the trachea contained two such lesions. 
Abdominal Organs.-One of the mesenteric glands contained a single caseous tubercle rather smaller than a pea.

\section{Calf $2 \mathrm{I}$.}

Bull calf. Admitted 28th July I9I I. Submitted to the ophthalmic tuberculin test on the following day, with negative result.

On the 4th August it was tested subcutaneously with tuberculin. The temperature in the afternoon of the previous day had been $1035^{\circ}$, and at the time of injection it was $102.3^{\circ}$. The highest temperature recorded during the following eighteen hours was $1039^{\circ}$, at the ninth hour.

On the Ioth August it was inoculated intravenously with Io $\mathrm{mg}$. of avian culture. At the time of inoculation the temperature was $\mathrm{IO}_{2} 4^{\circ}$, and the highest temperature during the following fifteen hours was $1045^{\circ}$, at the fifteenth hour.

On the 2nd November it was inoculated intravenously with $40 \mathrm{mg}$. of avian culture. At the time of inoculation the temperature was $103.8^{\circ}$, and during the following twelve hours the highest temperature was $107^{\circ} 2^{\circ}$, at the sixth hour.

On the 2oth July I9I 2 the animal was inoculated subcutaneously on the left side of the neck with $20 \mathrm{mg}$. of culture of bovine tubercle bacilli.

On the following day the temperature was $102.2^{\circ}$, and up till the 3 Ist July the highest temperature recorded was IO2. $8^{\circ}$. From the ist to the 7 th August the temperature fluctuated between $104.8^{\circ}$ and IOI. $7^{\circ}$. On the 8th August it was 101 $6^{\circ}$, and up till the 20th August the highest temperature recorded was $103^{\circ}$, except on $14^{\text {th }}$ and $I 5$ th August, when the animal was tested with tuberculin. Between the 2 Ist and 3 Ist August the highest temperature was 102. ${ }^{\circ}$. Afterwards the animal's temperature remained normal.

On the 2 Ist July a swelling 3 inches in its greatest diameter had formed at the seat of inoculation, and the adjacent prescapular gland felt to be about the size of a hen's egg. On the Ioth August the local swelling had become reduced in size, having a diameter of about $\mathrm{I} \frac{1}{2}$ inches. It was well defined and slightly fluctuating on pressure. The prescapular gland had increased in size, and was now about three times the normal bulk. On the 17th August the local swelling was about 2 inches in diameter, and the gland had become enormously enlarged, measuring about Io inches in length by 5 inches in breadth.

The animal was killed on the I6th December I9I 2 , and the postmortem examination showed the following lesions:-

General condition fair.

At the seat of inoculation at the left side of the neck there was a swelling about the size of a walnut, and composed of dense fibrous tissue. Towards its centre this had a brownish tinge, but it was free from actual caseation, or other distinct evidence of tuberculosis.

The prescapular gland on the same side was about three times the normal size, and converted into a sac containing caseo-purulent material.

Thoracic Organs.-The lungs contained about three dozen tubercles varying in size from a pea downwards. These had thick capsules enclosing a small amount of caseous material.

The right bronchial gland contained three, and the left bronchial gland 
four, tubercles, varying in size from a pea to a millet seed. These contained caseo-purulent material.

Abdominal Organs.-One caseo-purulent tubercle, about $2 \mathrm{~mm}$. in diameter, was present in the substance of the spleen, and two similar tubercles were found in the substance of the liver.

$$
\text { Calf } 4^{8} \text {. }
$$

Bull calf. Admitted 3rd November I9II. On the $7^{\text {th }}$ November it was submitted to the ophthalmic and intracutaneous tuberculin tests, with negative results.

On the I 4th November it was tested subcutaneously with tuberculin. At the time of injection the temperature was $103.2^{\circ}$, and the highest temperature recorded during the following fifteen hours was $104^{\circ}$, at the sixth hour.

On the $25^{\text {th }}$ November the animal was inoculated intravenously with $20 \mathrm{mg}$. of culture of avian tubercle bacilli. At the time of inoculation the temperature was $103^{\circ} 8^{\circ}$, and the highest temperature recorded during the following fifteen hours was $104^{\circ} 2^{\circ}$, at the sixth and twelfth hours.

On the I 9 th January I 9 I 2 the animal was inoculated intravenously with $30 \mathrm{mg}$. of culture of avian tubercle bacilli. At the time of inoculation the temperature was $1024^{\circ}$. At the third hour after inoculation it was $1016^{\circ}$, and it steadily rose to $106^{\circ}$, at the fifteenth hour.

On the 2oth July the animal was inoculated subcutaneously on the left side of the neck with $20 \mathrm{mg}$. of culture of bovine tubercle bacilli.

On the day of inoculation the temperature was $103^{\circ}$, and from that date until the 17 th August it did not rise above $103.2^{\circ}$, except on I4th August, when the animal was tested with tuberculin. On the 17 th August it was $105^{\circ} 2^{\circ}$, and during the following three days it varied from $1044^{\circ}$ to $105^{\circ}$. On the 2 Ist August it was $103^{\circ}$. From that date until the $13^{\text {th }}$ October it never rose above IO $24^{\circ}$, with the exception of rises occurring on 25 th and 30 th September, when tuberculin tests were carried out. On the I4th October it was $103^{\circ}$, and from that date until the 28 th October it varied from a minimum of $1014^{\circ}$ to a maximum of $102.8^{\circ}$

At the seat of inoculation on the left side of the neck there developed a swelling which on the 27 th July was 3 inches in diameter and about $I_{2} \frac{1}{2}$ inches in thickness, hard and rather painful. On the Ioth August the swelling, which was about the same size, was fluctuating, and by the 26th August it was about the size of a hen's egg. The adjacent prescapular gland attained a maximum size of 10 inches in length by 5 inches in width by the I7th August, after which it decreased.

The animal was killed on the Ist November 1912, and the following lesions were found at the post-mortem examination :-

Condition good.

At the seat of inoculation on the left side of the neck there was a circumscribed swelling about 2 inches in diameter, which was fluctuating but showed no signs of having burst. On section this was found to be composed of a greenish-yellow custard-like material enclosed in a thin fibrous capsule. The prescapular gland measured $14 \mathrm{~cm}$. by $9 \mathrm{~cm}$., and on section was found 
to contain two cavities containing firm caseous material which was distinctly gritty and a little clear liquid.

Thoracic:Organs.-The bronchial glands each contained about a dozen tubercles of about 3 or $4 \mathrm{~mm}$. in diameter, and composed of yellow, caseous material. The mediastinal gland contained one exactly similar tubercle. One of the prepectoral glands was about the size of a pigeon's egg, and on section was found to have been almost entirely converted into firm, caseous material.

About two dozen tubercles, varying in size from a split pea down to quarter that size, were discovered in the two lungs. On section they were found to be composed of a greyish capsule enclosing caseous contents. The parietal pleura showed some scarcely visible excrescences between the ribs, and similar excrescences were present on the diapbragm.

\section{Calf 53 .}

Heifer calf. Admitted 3rd November 19II. On the 7 th November it was submitted to the ophthalmic and intracutaneous tuberculin tests, with negative results.

On the I4th November it was tested by the subcutaneous tuberculin test. At the time of injection the temperature was $104^{\circ}$, and the highest temperature recorded during the following fifteen hours was $104.2^{\circ}$, at the ninth hour.

On the $25^{\text {th }}$ November the animal was inoculated intravenously with $20 \mathrm{mg}$. of culture of avian tubercle bacilli. At the time of inoculation the temperature was $102.8^{\circ}$, and during the following fifteen hours the highest temperature recorded was $103.5^{\circ}$, at the twelfth hour.

On the Igth January I9I 2 the animal was inoculated intravenously with $40 \mathrm{mg}$. of avian tubercle bacilli. At the time of inoculation the temperature was $102 \cdot 2^{\circ}$, and the highest temperature recorded during the following fifteen hours was $106^{\circ} 4^{\circ}$, at the twelfth hour.

On the 2oth July the animal was inoculated subcutaneously on the left side of the neck with $40 \mathrm{mg}$. of culture of bovine tubercle bacilli.

On the day of inoculation the temperature was $103.8^{\circ}$, and it did not again reach $103^{\circ}$ until the 3 oth July. On the Ist and 2nd August it was $103.8^{\circ}$ and $103.4^{\circ}$ respectively, and on $14^{\text {th }}$ August there was an elevation of temperature during a tuberculin test. Afterwards up to the I 4 th October it did not exceed $103^{\circ}$, except as the result of a tuberculin test.

At the seat of inoculation on the left side of the neck there developed a swelling which on the 27 th July measured about $2 \frac{1}{2}$ inches in surface diameter. On the Ioth August it was a little reduced in size, but was very soft and just commencing to discharge. On the I 7 th August it measured 3 inches in diameter and was firm. On the 26th August it measured 4 inches in diameter. The adjacent prescapular gland had attained a maximum size of 8 inches in length by 5 inches in width by the 3 rd August, after which it decreased, measuring on the 26 th August 5 inches by $2 \frac{1}{2}$ inches.

The animal was killed on the 3 Ist October 19I2, and the following lesions were found at the post-mortem examination.

General condition good.

At the seat of inoculation there was a swelling about the size of a turkey's egg, which was covered on its surface with dried crusty material. On section it 
was found to be composed of fibrous tissue with a cavity containing about $\frac{1}{4}$ oz. of greenish-yellow caseous material, and a few smaller caseous centres. The prescapular gland was about twice the normal size, and on section was found to contain two cavities, each surrounded by a layer of persistent gland tissue. The cavities contained custard-like material, together with about $\mathbf{I}$ oz. of clear liquid. The walls of each cavity were distinctly gritty. One of the prepectoral glands on the left side was slightly enlarged. It was found on section to be almost entirely converted into caseous material.

Thoracic Organs.-Each lung contained about forty tubercles varying in size from a small pea downwards. On section these were found to be composed of a greyish capsule enclosing a greyish centre. The majority of the tubercles were situated in the anterior lobes, and close to the anterior and inferior borders of the main lobes.

Abdominal Organs, - The liver contained three tubercles about the size of oat grains.

\section{Calf 55 .}

Bull calf. Admitted 3rd November I9I I. On the 7 th November the animal was subjected to an intracutaneous tuberculin test, with negative result. The ophthalmic test was not carried out because the animal had marked conjunctivitis of the right eye.

On the I4th November the animal was subjected to a subcutaneous tuberculin test. At the time of injection the temperature was $103.5^{\circ}$, and the highest temperature recorded during the following fifteen hours was $104^{\circ} I^{\circ}$, at the ninth hour.

On the $25^{\text {th }}$ November the animal was inoculated intravenously with $20 \mathrm{mg}$. of culture of avian tubercle bacilli. At the time of inoculation the temperature was $\mathrm{IO}_{2} 5^{\circ}$, and the highest temperature recorded during the following fifteen hours was $107^{\circ} I^{\circ}$, at the sixth hour.

On the Igth January 1912 the animal was inoculated intravenously with $50 \mathrm{mg}$. of culture of avian tubercle bacilli. The temperature at the time of inoculation was $102^{\circ} 6^{\circ}$, and the highest temperature recorded during the fifteen hours following inoculation was $105^{\circ}$, at the ninth and twelfth hours.

On the 2oth July the animal was inoculated on the left side of the neck with $50 \mathrm{mg}$. of culture of bovine tubercle bacilli.

On the day of inoculation the temperature was $103^{\circ}$, and on the 2 Ist and 22 nd July it was $103.4^{\circ}$ and $103^{\circ}$, respectively. From this date until the 2nd Angust it did not rise above $102 \cdot 6^{\circ}$, but on that date it was $103^{\circ}$. From the 3 rd August until the 28 th October the temperature exceeded $103^{\circ}$ on two occasions only. On the 7 th August it was $103^{\circ} I^{\circ}$, and on the I 7 th it was $103.2^{\circ}$.

At the seat of inoculation on the left side of the neck there had formed by the 27 th July an elongated swelling measuring 6 inches in length, 3 inches in width, and 2 inches in thickness. By the 3 rd August this swelling had decreased considerably in size, and measured only 3 inches in length by 2 inches in width. On the 26 th August there was a swelling about the size of a hen's egg superposed to a flattened swelling which extended a little beyond its limits. From this date onwards the swelling decreased in size, and by the 2 ist October it was the size of a pigeon's egg and had burst. The adjacent prescapular gland attained a maximum size of about twice the normal by the 26 th August, after which it underwent little alteration in size. 
The animal was killed on the Ist November I9I2, and the following lesions were found at the post-mortem examination :-

General condition very good.

At the seat of incculation on the left side of the neck there was a circumscribed swelling a little smaller than a hen's egg. The skin covering the swelling was thickened and showed on its surface a quantity of crusty material, but there was no recent discharge. On section it was found that the bulk of the swelling was composed of fibrous tissue. In its centre there was a cavity about the size of a horse bean containing a little reddish fluid, and there were a few small caseous centres embedded in the fibrous tissue.

The prescapular gland was scarcely enlarged, and on section was found to contain about a dozen tubercles, varying in size from a horse bean down to a pin's head. These contained greenish-yellow caseo-calcareous material.

Thoracic Organs.-After a very minute examination of the lungs two yellow caseous tubercles about 4 or $5 \mathrm{~mm}$. in diameter were found in the right lung, and one similar tubercle in the left.

The pleura covering the lungs showed well-marked grey excrescences, especially on the inner surface of the lungs and along the lower border of the main lobes. Many of the excrescences were pendulous, and some were of a dark red colour. The parietal pleura showed similar outgrowths. These were particularly marked on the diaphragm, where at places the growths were $\frac{1}{4}$ inch in thickness. The pleura covering the chest walls showed excrescences running in parallel ridges between the ribs. Similar growths were present on the outer surface of the pericardium.

There was one circumscribed yellowish nodule about the size of a split pea in the wall of the left ventricle of the heart.

Abdominal Organs.-On each side of the centre of the diaphragm there were diffuse crescentic excrescences of a pinkish-grey colour, and about $\frac{1}{16}$ to $\frac{1}{8}$ inch in thickness. Similar excrescences were found on the peritoneum at the highest part of the loins, and the omentum was almost covered with growths of the same kind. On the surface of the rumen there were innumerable greyish translucent nodules, the majority of which were about the size of barley grains.

On the surface of the liver there were a few greyish outgrowths, each about the size of an oat seed. The surface of the spleen was covered with a very large number of circumscribed greyish excrescences about the size of millet seeds.

\section{Calf 28 (Control).}

Bull calf. Admitted Ioth August 19Ir. Submitted to the ophthalmic tuberculin test on the 2 Ist September, with negative result.

On the 27 th September it was again tested by the ophthalmic method, and at the same time subcutaneously. There was again no reaction to the ophthalmic test. The temperature at the time of injection of the tuberculin was $103.6^{\circ}$, and it had risen to $105^{\circ} 4^{\circ}$ at the sixth hour, after which it steadily fell to $102.9^{\circ}$ at the fifteenth hour. During the fortnight preceding the test the temperature had been $104^{\circ}$ or more on eight days, and $105^{\circ}$ on two days.

The animal was again tested by the subcutaneous and intradermic methods on the $4^{\text {th }}$ June 19I2. The temperature was $102^{\circ}$ at the time of injection, and it did not exceed that during the following fifteen hours. There was no reaction to the intradermic test.

On the 2oth July the animal was inoculated subcutaneously on the left side of the neck with $20 \mathrm{mg}$. of culture of bovine tubercle bacilli.

On the day of inoculation with bovine tubercle bacilli the animal's 
temperature was $1024^{\circ}$, and from 2 ist to $23 \mathrm{rd} \mathrm{July} \mathrm{it} \mathrm{was} 102 \cdot 6^{\circ}$. After this it rose gradually, reaching $1044^{\circ}$ on the 26 th July. On the $27 \mathrm{th}, 28$ th and 29 th July it varied a little on either side of $103^{\circ}$. On the 30 th July it was $105^{\circ}$, and during the next two days it rose to $106^{\circ}$, falling again to $104^{\circ} 6^{\circ}$ on 3 rd August, and rising to $105^{\circ} 4$ on the 6th August. From this date until 2 ist August it was very variable, oscillating between $104^{\circ} 8^{\circ}$ and $101.5^{\circ}$. From the 22nd August until 28th October the temperature rose above $103^{\circ}$ on two occasions only, viz., 8th September, when it was $103.2^{\circ}$, and I 7 th September, when it was $103^{\circ}$.

On the 27 th July there was a flattened swelling extending from the seat of inoculation (about the middle of the neck) to the bottom of the neck, and the adjacent prescapular gland was about twice the normal size. On 3 rd August there was a swelling the size of a walnut at the seat of inoculation, and a flattened swelling extending from that point down the neck with an ill-defined lower extremity. The prescapular gland was about four times the normal size. On the Ioth August the swelling at the seat of inoculation measured 4 inches in length by 2 inches in width, and it was fluctuating at the point of inoculation. The prescapular gland measured 6 inches in length and $3 \frac{1}{2}$ inches in width, and was very painful. On the $I 7^{\text {th }}$ August it was found that the swelling on the side of the neck had burst, and it was covered with dark crusts. The gland on this date was $7 \frac{1}{2}$ inches long and 3 inches broad. On the 3 Ist August the swelling appeared to have ceased discharging, but a week later there was a lot of creamy discharge escaping. On the 14th September discharge had again ceased, and the prescapular gland had decreased somewhat in size. On the 3oth September, at the seat of inoculation, there was a swelling the size of a small hen's egg placed superficially to a flattened swelling. On the r 4 th October the flattened swelling was only just appreciable, and the circumscribed swelling had decreased to the size of a pigeon's egg.

The animal was killed on the 3 Ist October 1912, and the following lesions were found at the post-mortem examination :-

General condition good.

At the seat of inoculation on the left side of the neck there was a firm swelling about the size of a hen's egg, which was discharging yellow, custardlike material. On cutting into this it was found to consist of fibrous tissue, containing in its centre about $\frac{1}{2}$ oz. of greenish-yellow, custard-like material. The prescapular gland was about twice the normal size. On section the lower part was found to have been converted almost entirely into firm, greyish-yellow, caseous material containing some calcareous particles. The upper portion of the gland contained only one calcareous tubercle, about the size of a bean.

Thoracic Organs.-The left bronchial gland contained two tubercles, one about the size of a pin's head, and the other just visible. They were both yellow and caseous. The right bronchial gland contained about half a dozen well-defined caseous tubercles about the size of one or two pin's heads.

Lungs. - The right lung contained close to its posterior border half a dozen tubercles about the size of barley grains. On section these were found to be composed of greyish-red, fibrous-looking capsule and a yellow caseous centre, which could easily be separated. In the same position in the left lung there was a similar number of similar tubercles, varying in size from a barley grain down to a couple of pin's heads. 
Abdominal Organs.-On the diaphragmatic surface of the liver there was at number of just visible greyish translucent excrescences.

\section{Calf 29 (Control).}

Bull calf. Admitted Ioth August I9I I. On the 2 Ist September I9I I it was tested with tuberculin by the ophthalmic method, and there was no reaction.

It was again tested in the same way and also by the subcutaneous method on the 27th September. There was no reaction to the eye test, but the temperature rose from $I O{ }^{\circ} 9^{\circ}$ at the time of injection to $105^{\circ}$ at the sixth hour, after which it fell steadily to $1018^{\circ}$ at the fifteenth hour. During the preceding fortnight the animal's temperature had generally been over $103^{\circ}$, and on one occasion touched $104^{\circ}$.

The animal was again tested on the 4 th June 19 I 2 , this time by the intracutaneous and subcutaneous methods. The temperature was IOI $4^{\circ}$ at the time of injection, and the highest temperature during the following fifteen hours was $1024^{\circ}$, at third and sixth hours. There was no reaction to the intracutaneous test.

On the 20 th July I9I 2 the animal was inoculated subcutaneously on the left side of the neck with $40 \mathrm{mg}$. of culture of bovine tubercle bacilli.

On the day of inoculation the animal's temperature was $102^{\circ}$. From the day of inoculation until the 26 th July the temperature steadily rose to a maximum of $103^{\circ} 6^{\circ}$. On the 27 th, $28 \mathrm{th}, 29 \mathrm{th}$, and 3 oth it was $103^{\circ}$. On the 3 Ist it rose to $1048^{\circ}$, and from the ist until the 8th August it was somewhat irregular, oscillating between $103.2^{\circ}$ and $104.8^{\circ}$. From the 9 th to the 30 th August the temperature varied irregularly from $10 \mathrm{I}^{\circ}$ to $1045^{\circ}$. During the month of September the temperature did not rise above $103^{\circ} 2^{\circ}$, except on the 27 th, when it reached $1042^{\circ}$, and after this it rose to $103^{\circ}$ on one occasion only.

On the 27th July a flattened swelling measuring 4 inches by 3 inches had formed at the seat of inoculation, and the prescapular gland on the same side was rather less than twice the normal size. On the 3 rd August the local swelling measured 3 inches in diameter and about I inch in thickness at its centre, the prescapular gland on this date being nearly three times the normal size. On Ioth August the local swelling measured 4 inches in diameter by $2 \frac{1}{2}$ inches in thickness, and was hard and tense. The prescapular gland was about the same size. On the I 7 th August the local swelling had decreased a little in size, and the prescapular gland measured 7 inches in length by 4 inches in width. On the 7 th September the local swelling was found to have burst, and it continued to discharge until the 24th September. By the 7 th October it measured 2 inches in diameter, and its surface was covered with crusty discharge.

The animal was killed on the ist November 1912, and the following lesions were found at the post-mortem examination :-

General condition good.

At the seat of inoculation there was a circumscribed swelling about the size of a turkey's egg, which on section was found to be composed for the 
most part of greyish fibrous-looking tissue containing a number of pinkish calcareous centres. In the centre there was a cavity measuring about half an inch in diameter, and containing some greenish-yellow, custard-like material. The prescapular gland measured 5 inches in length, and on section it was found that in its upper part there was a very large number of caseo-purulent tubercles about the size of a pin's head. The lower part of the gland was almost entirely converted into a cavity containing a large amount of yellow caseo-purulent material and a small amount of clear liquid.

Thoracic Organs.-The right and left bronchial glands contained a number of yellow caseous tubercles about the size of a pin's head, and exactly similar tubercles were found in the mediastinal glands. Two of the prepectoral glands were enlarged to about the size of a small hen's egg, and on section was found to have been almost entirely converted into a firm caseous material.

The right lung contained about 200 tubercles varying in size from a barley grain to two or three pin's heads. These were more numerous in the anterior lobes than in the main lobe. On section they were found to be composed of a fairly thick fibrous-looking capsule enclosing yellow caseous contents. In the left lung there were exactly similar but less numerous tubercles.

Abdominal Organs.-The portal glands contained a fair number of pinhead tubercles similar to those found in the bronchial glands. The diaphragmatic surface of the liver showed under the capsule about a score of tubercles about 3 or $4 \mathrm{~mm}$. in diameter, and similar tubercles were found scattered through the parenchyma.

Each longitudinal incision into the substance of the spleen exposed about a dozen yelow caseous tubercles somewhat larger than those in the liver.

\section{SERIES IV.}

As the following Table shows, this series included twelve calves, all of which were tested as to their immunity by inoculation with

\begin{tabular}{|c|c|c|c|c|c|c|}
\hline No. & $\begin{array}{c}\text { Date of } \\
\text { Vactination. }\end{array}$ & $\begin{array}{c}\text { Nature of } \\
\text { Bacilli. }\end{array}$ & $\begin{array}{c}\text { Dose in } \\
\text { Milli- } \\
\text { grammes. }\end{array}$ & $\begin{array}{c}\text { Date of Test } \\
\text { Inoculation } \\
\text { with Bovine } \\
\text { Bacilli. }\end{array}$ & $\begin{array}{c}\text { Dose in } \\
\text { Milli- } \\
\text { grammes. }\end{array}$ & $\begin{array}{l}\text { Date of } \\
\text { Death. }\end{array}$ \\
\hline $6 \mathbf{I}$ & $20 \cdot 2 / 13$ & Human & 10 & $21 / 6 / \mathrm{I}_{3}$ & 50 & $3 / 12 / 13$ \\
\hline 62 & , , & $n$ & ", & , & 25 & , \\
\hline 63 & 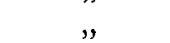 & 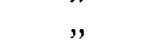 & , & , & 50 & " \\
\hline 64 & , & $"$ & , & $"$ & 25 & $4 / 12 / 13$ \\
\hline 65 & , & $"$ & $"$ & $"$ & 50 & $"$ \\
\hline $7 \mathrm{I}$ & ", & Avian & $"$ & $"$ & 50 & \\
\hline 72 & $"$ & $"$ & $n$ & $"$ & 25 & $5 / 12 / 13$ \\
\hline 73 & $"$ & $"$ & ", & " & 50 & , \\
\hline 74 & $"$ & ” & " & $"$ & 25 & $22 / 10 / 13$ \\
\hline 75 & $"$ & $"$ & $"$ & $"$ & 50 & $5 / 12 / 13$ \\
\hline 82 & \multicolumn{3}{|c|}{ Unvaccinated control. } & , & 25 & $25 / 7 / 13$ \\
\hline 83 & , & " & & $"$ & 50 & $4 / 8 / 13$ \\
\hline
\end{tabular}


bovine tubercle bacilli on the 2Ist June I9I3. Two of the calves were unvaccinated healthy controls, five had been vaccinated once with human tubercle bacilli, and the remaining five with avian tubercle bacilli.

The culture which furnished the avian bacilli for vaccination had been incubated for sixty-three days, and the one which furnished the human bacilli for ninety-six days. The bovine bacilli used for the test inoculation were from a culture which had been incubated for twenty-five days.

The vaccinated calves were all of the Shorthorn type, and about three or four months old when purchased for the experiments in January. The two control calves were of the same type, but it ought to be noted that they were smaller and probably a little younger than the average of the vaccinated animals, although as large as the smallest of these.

\section{Calf 6I.}

Bull calf. Admitted $7^{\text {th }}$ January I9I3. The temperature was taken twice daily from 7 th to $27^{\text {th }}$ January, and was found to vary from $\mathrm{IOI}^{\circ}$ to $104^{\circ}$.

On the 28 th January the animal was submitted to the subcutaneous, intracutaneous, and ophthalmic tuberculin tests. At the time of injection the temperature was $102^{\circ}$, and the highest temperature recorded during the following fifteen hours was $103.8^{\circ}$, at the twelfth hour. The intracutaneous and ophthalmic tests gave entirely negative results.

On the 2oth February the animal was inoculated intravenously with $10 \mathrm{mg}$. of culture of human tubercle bacilli. The temperature at the time of inoculation was $102^{\circ} 2^{\circ}$, and the highest temperature recorded during the twelve hours following was $1034^{\circ}$, at the ninth hour.

On the 21st June it was inoculated subcutaneously on the left side of the neck with $50 \mathrm{mg}$. of culture of bovine tubercle bacilli.

On the day of inoculation the animal's temperature was $102^{\circ}$. On the 23 rd June the temperature rose to $105^{\circ} 2^{\circ}$, and between that date and 26 th June it varied from $104^{\circ}$ to $105^{\circ} 2^{\circ}$. From the 26 th June until 8th August the temperature did not exceed $103^{\circ}$, and the highest temperature recorded up to the Ioth September was $1034^{\circ}$.

At the seat of inoculation there formed a swelling which gradually increased in size until, on the 15 th August, it measured 5 inches by 2 inches, and was rather soft. The adjacent prescapular gland had increased to about three times the normal size. The local swelling was opened on the 9 th September.

The animal was killed on the 3rd December 1913, and the following lesions were found at the post-mortem examination :-

General condition moderate.

At the seat of inoculation there was a swelling about the size of a small hen's egg, and this was discharging a pale, greenish-yellow, thick pus. On section the swelling was found to consist of a thick, fibrous wall enclosing a cavity filled with pus similar to that which was being discharged. The prescapular gland on the same side measured $8 \mathrm{~cm}$. by $4 \mathrm{~cm}$., and on section was found to contain a cavity about the size of a walnut, enclosing pus similar 
to that found in the local lesion. One gland belonging to the tracheal chain about the middle of the neck was about the size of a horse bean, and was full of similar pus.

\section{Calf 62.}

Heifer calf. Admitted 7 th January I9I3. The animal's temperature was taken twice daily from the 7 th to 27 th January, and fluctuated between $101^{3}$ and $103^{\circ} 8^{\circ}$.

On the 28th January the animal was submitted to the tuberculin test by the subcutaneous, intracutaneous, and ophthalmic methods. The temperature at the time of injection was $1022^{\circ}$, and the highest temperature recorded during the following fifteen hours was $103^{\circ} 8^{\circ}$, at the fifteenth hour. The intracutaneous and ophthalmic tests were entirely negative.

On the 2oth February the animal was inoculated intravenously with Io $\mathrm{mg}$. of culture of human tubercle bacilli. The maximum temperature recorded during the following fifteen hours was $102.6^{\circ}$ at the ninth hour.

On the 2 Ist June the animal was inoculated subcutaneously on the left side of the neck with $25 \mathrm{mg}$. of culture of bovine tubercle bacilli.

The temperature on the day of inoculation was $1024^{\circ}$. On the 22nd June it had fallen $1^{\circ}$. On the 23 rd June it was $103^{\circ} 6^{\circ}$, and on the $24^{\text {th }}$ it had fallen again to $1022^{\circ}$. From the $25^{\text {th }}$ to the 28th June it varied from $1034^{\circ}$ to $1044^{\circ}$, and from the latter date until the 8th August it did not reach $103^{\circ}$, save on the occasion of a tuberculin test carried out on the 2 nd and 3 rd July.

By the 7 th July there had developed at the seat of inoculation a swelling the size of a pigeon's egg, superposed to a flat swelling measuring 2 inches by $\mathrm{I}$ inch, and very little alteration in the size of this swelling occurred until the 9 th September, when it was opened. The adjacent prescapular gland by the 7 th July had attained a size twice the normal, and this was maintained until the I 5 th August, when it was about three times the normal size.

The animal was killed on the 3rd December 19I3, and the following lesions were found at the post-mortem examination :-

General condition moderate.

On the left side of the neck there was a firm fibrous nodule about the size of a walnut, which on section was found to contain three dry, caseous centres a little larger than peas. The prescapular gland on the same side was about half as large again as normal, and it contained three centres of exactly the same nature about the size of horse beans.

$$
\text { Calf } 63 .
$$

Bull calf. Admitted 7 th January 19I3. The animal's temperature was taken twice daily from that date to the 27 th January, and was found to fluctuate between $100^{\circ}$ and $103.6^{\circ}$. On the 28 th January the animal was submitted to the tuberculin test by the subcutaneous, intracutaneous, and ophthalmic methods. At the time of injection the animal's temperature was $I^{\circ} I^{\circ} 2^{\circ}$, and the highest temperature recorded during the following fifteen hours was $1034^{\circ}$, at the third hour. The intracutaneous and ophthalmic tests were quite negative. 
On the 2oth February it was inoculated intravenously with Io mg. of culture of human tubercle bacilli, and the highest temperature recorded during the following fifteen hours was $102.6^{\circ}$, at the ninth hour.

On the 2 Ist June it was inoculated subcutaneously on the left side of the neck with $50 \mathrm{mg}$. of culture of bovine tubercle bacilli.

The temperature on the day of inoculation was $102^{\circ}$, and by the 23 rd it had risen to $103.6^{\circ}$, which was maintained until the $25^{\text {th. }}$ From the 26 th to the 3 oth June the temperature did not rise above $102^{\circ} 6^{\circ}$, and on the Ist July it was $103^{\circ} 6^{\circ}$. From the 2nd July until the 7 th August the temperature rose to $103^{\circ}$ or over on two occasions only, viz, on the and July, when the animal was tested with tuberculin, and on the 22 nd July, when it was $103^{\circ}$.

By the 7 th July there had developed at the seat of inoculation on the side of the neck a flat swelling measuring 4 inches by 2 inches, and superposed to this there was a soft swelling about the size of a hen's egg. The adjacent prescapular gland felt to be about twice the normal size. By the 2 Ist July the flat swelling on the side of the neck measured 7 inches by 5 inches, and there were superposed to it two soft swellings, one about the size of a hen's egg and the other a little smaller. On the 28 th July there was a fluctuating swelling about 6 inches in diameter, with a soft circumscribed swelling measuring about 2 inches in diameter superposed to it. This condition was maintained until the 29th August, when the swelling was opened and about I litre of pus collected from it. The adjacent prescapular gland steadily increased in size, until on 28th August it was about four times the size and firm.

The animal was killed on the 3 rd December I9I3, and the following lesions were found at the post-mortem examination :-

General condition moderate.

At the seat of inoculation on left side of the neck there were three rounded swellings varying in diameter from $\frac{3}{4}$ inch to $1 \frac{1}{2}$ inches. On section these were found to have a fibrous wall measuring about $\frac{1}{8}$ inch in thickness, with pale, greenish-yellow, thick, purulent contents. A fourth abscess of exactly the same nature and about $I \frac{1}{2}$ inches in diameter was found embedded in the superficial muscles of the neck. The prescapular gland on the same side measured $12 \mathrm{~cm}$. by $8 \mathrm{~cm}$., and on section it was found that only one piece of normal gland tissue about the size of a filbert nut remained in the upper portion of the gland. The whole of the remainder of the gland was converted into pus-like material exactly similar to that seen in the local lesion.

Thoracic Lesions. - The posterior mediastinal gland contained two centres, one about the size of a horse bean and the other as large as a pea, enclosing exactly similar pus. The left prepectoral gland was as large as a hen's egg and entirely filled with thick, yellowish-green pus. The left pharyngeal gland was about twice the normal size, and contained an exactly similar lesion about the size of a filbert nut.

$$
\text { Calf } 64 .
$$

Heifer calf. Admitted 7 th January I9I3. The animal's temperature was taken twice daily from that date until the $27_{\text {th }}$ January, and it was found to fluctuate between $101^{\circ}$ and $103.6^{\circ}$. On the 28 th January the animal was submitted to the tuberculin test by the subcutaneous, intracutaneous, and ophthalmic methods. The tempera- 
ture at the time of inoculation was $102^{\circ}$, and the highest temperature recorded during the following fifteen hours was $103^{\circ}$, at the third hour. The other two tests were entirely negative.

On the 2oth February the animal was inoculated intravenously with Io $\mathrm{mg}$. of culture of human tubercle bacilli, and the highest temperature recorded during the following fifteen hours was $103^{\circ} 8^{\circ}$, at the twelfth hour.

On the 2 Ist June the animal was inoculated subcutaneously on the left side of the neck with $25 \mathrm{mg}$. of culture of bovine tubercle bacilli.

The temperature on the day of inoculation was IO2.4. From the 23 rd June until the 26 th June it varied from $103^{\circ}$ to $105^{\circ}$, reaching

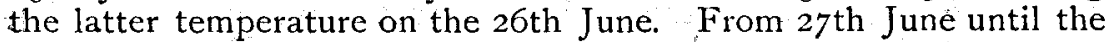
7 th August it did not exceed $1026^{\circ}$, save on the 2nd July, when a tuberculin test was carried out.

By the 7 th July there was a circumscribed swelling at the seat of inoculation, which measured 3 inches by 2 inches. This swelling had softened somewhat by the 2 Ist July. On the I 5 th August there were in addition to this swelling three soft circumscribed swellings each about the size of a pigeon's egg. On the 2and August all these had become merged into a single swelling, which measured 5 inches by 3 inches. The adjacent prescapular gland slowly increased in size, until on the 15 th August it was about three times as large as normal.

The animal was killed on the $4^{\text {th }}$ December 1913, and the following lesions were found at the post-mortem examination :-

General condition moderate.

At the seat of inoculation on the left side of the neck there was a circumscribed swelling measuring about $2 \frac{1}{2}$ inches in diameter. On section it was found to consist of a thick fibrous wall enclosing yellowish creamy pus which was not gritty. The adjacent prescapular gland, which was not greatly enlarged, contained a single centre of caseous material about the size of a horse bean.

Thoracic Organs.-The pleura covering the anterior half of each lung was covered with a continuous layer of pinkish-grey granular new tissue. That covering the posterior half of each lung had scattered over it, in the proportion of about one dozen to the square inch, little flattened projections varying in size from a barley grain downwards. In addition to these the pleura covering the posterior half of the right lung showed five larger mushroom-like growths measuring $\frac{1}{2}$ inch in diameter. Along the lower border of the middle third of each lung there was a fringe-like growth which attained a length in some places of $\frac{3}{4}$ inch. Almost the whole of the costal and diaphragmatic pleura was covered with a thin pinkish-grey, granular, tuberculous growth. At some places it was continuous, and at others in the form of scattered patches. The exterior of the pericardium was covered with a growth exactly similar to that covering the anterior half of each lung.

$$
\text { Calf } 65 .
$$

Heifer calf. Admitted 7 th January I9I3. The animal's temperature was taken twice daily from the date of admission until the 27 th January, and was found to fluctuate between $101^{\circ}$ and $104^{\circ}$.

On the 28 th January the animal was subjected to the tuberculin test by the subcutaneous, intracutaneous, and ophthalmic methods. 
The temperature at the time of injection was $102^{\circ}$. At the third hour it had risen to $104^{\circ} 6^{\circ}$, and from the sixth to the ninth hours it was below $104^{\circ} 5^{\circ}$. At the fifteenth hour it had risen again to $105^{\circ}$. The intradermic and ophthalmic tests were entirely negative.

On the 2oth February the animal was inoculated intravenously with Io $\mathrm{mg}$. of culture of human tubercle bacilli, and during the fifteen hours following the inoculation the temperature steadily rose, reaching a maximum of $107^{\circ}$ at the twelfth hour.

On the 2 Ist June the animal was inoculated subcutaneously on the left side of the neck with $50 \mathrm{mg}$. of culture of bovine tubercle bacilli.

The temperature on the day of inoculation was $101.8^{\circ}$. On the 22nd June it was $102^{\circ}$, on the $23 \mathrm{rd}$ it was $106.2^{\circ}$, and on the following three days it fluctuated between $103^{\circ}$ and $103^{\circ} 6^{\circ}$. From the $27^{\text {th }}$ June until the 7 th August it did not rise above $102.6^{\circ}$, except on the and July, when the animal was tested with tuberculin.

At the seat of inoculation there developed a flattened swelling which by the 7 th July measured 2 inches by $\mathrm{I}$ inch by $\frac{3}{4}$ inch. On the 28 th July it measured 3 inches in diameter by $1 \frac{1}{2}$ inches in thickness. On the I 5 th August it was rather more circumscribed, measuring about $2 \frac{1}{2}$ inches in diameter, and was quite soft. A week later the swelling measured $4 \frac{1}{2}$ inches by 2 inches, and on the 9 th September it was opened. The adjacent prescapular gland had become enlarged to twice the normal size by the 7 th July, and during the next two. months it did not undergo any alteration in size. Afterwards it gradually declined.

The animal was killed on the $4^{\text {th }}$ December I9I 3 , and the following lesions were found at the post-mortem examination :-

General condition moderate.

At the seat of inoculation at the left side of the neck there was a thickening of the skin and subcutaneous tissue measuring about 2 inches in diameter, but no centres of any kind could be found in it on section. The left prescapular gland was not sensibly enlarged, and contained two centres rather smaller than peas, the contents of which were almost completely calcified.

Thoracic Organs. - The pleura covering the middle third of the outer surface of each lung and the base of each lung showed an almost continuous layer of delicate pinkish-grey granular new tissue, and the anterior and posterior thirds of the outer surface of each lung showed scattered patches of similar tissue varying in size from $\frac{3}{4}$ inch in diameter downwards. The costal and diaphragmatic pleura showed exactly similar lesions with a distribution corresponding with that shown by the lesions on the visceral pleura. The left bronchial gland contained a single lesion about the size of a pea, with gritty caseous contents.

Abdominal Organs.-The omental peritoneum was practically covered with a continuous layer of pinkish-grey granular tuberculous growth. The peritoneum covering the stomachs showed a very close scattering of flattened tubercles varying in size from a pea downwards. One half of the spleen showed on both surfaces a layer of tuberculous tissue similar to that covering the omentum, the other half being quite free from such growth. Both surfaces of the liver showed numerous flattened grey outgrowths, varying in size from a millet seed downwards. The portal glands contained about a dozen tubercles about the size of millet seeds. The parietal peritoneum was most extensively affected on the floor of the abdomen, where there was a continuous layer of granular tissue like that covering the omentum. On the 
sides and the roof of the abdominal cavity the peritoneum showed scattered. patches of similar tissue of various sizes.

\section{Calf $7 \mathrm{r}$.}

Heifer calf. Admitted 7 th January 19I3. The animal's temperature was taken daily from that date until the 27 th January, and was found to fluctuate between $100.6^{\circ}$ and $104.8^{\circ}$.

On the 28 th January the animal was tested with tuberculin by the subcutaneous, intracutaneous, and ophthalmic methods. The temperature at the time of injection was $102.6^{\circ}$, and the highest temperature recorded during the following fifteen hours was $103^{\circ} 8^{\circ}$, at the twelfth hour. The other two tests were entirely negative.

On the 2oth February the animal was inoculated intravenously with Io $\mathrm{mg}$. of culture of avian tubercle bacilli, and the highest: temperature recorded during the following fifteen hours was $103^{\circ} 8^{\circ}$, at the ninth hour.

On the 2 Ist June the animal was inoculated subcutaneously on the left side of the neck with $50 \mathrm{mg}$. of culture of bovine tubercle bacilli.

The temperature on the day of inoculation was $103.6^{\circ}$. On the 22nd June it was IOI. $8^{\circ}$, and from this date until the 26 th it steadily rose to a maximum of $104^{\circ} 8^{\circ}$. From the 27 th until the Ist July the temperature was somewhat variable, fluctuating between $102.2^{\circ}$ and IO4. $4^{\circ}$. The animal was tested with tuberculin on the 2 nd July, and from the 3 rd July until the 7 th August the temperature reached $103^{\circ}$ on three occasions only, viz., July I ith, I6th and 26 th.

At the seat of inoculation on the left side of the neck there had developed by the 7 th July two circumscribed swellings, the larger one measuring a little over 2 inches in diameter and the smaller one about $I_{2}^{1}$ inches. These swellings persisted practically without alteration until the I2th September, when they were opened. The adjacent prescapular gland steadily increased in size until by the 28th July it was about four times the normal, after which it decreased.

The animal was killed on the 4 th December I9 3 , and the following lesions were found at the post-mortem examination :-

General condition moderate.

At the seat of inoculation on the side of the neck there was a thickened area of skin measuring about 2 inches in diameter and $\frac{1}{4}$ inch in thickness. On section two smaller areas of a brownish colour could be seen in the thickened skin, but no degenerated tissue of any kind was found. The left prescapular gland, which was slightly enlarged, contained two cavities, each about the size of a horse bean, filled with slightly gritty caseous contents, and two smaller cavities with exactly similar contents.

Thoracic Organs. - The visceral pleura covering the middle third of the outer surface of each lung showed an almost continuous layer of granular greyish-pink tuberculous tissue. The anterior and posterior thirds of the outer surface and the base of each lung showed scattered patches of similar tissue. The left bronchial gland contained two caseous lesions about the size of a pin's head. The posterior mediastinal gland contained one lesion of an exactly similar nature. .

Abdominal Organs. - The omentum was practically covered with a con- 
tinuous layer of pinkish.grey granular tuberculous tissue varying in thickness up to $\frac{1}{8}$ inch. The peritoneum covering the stomachs showed a fairly close scattering of flattened tubercles varying in size from a pea downwards. One half of the spleen showed tuberculous tissue exactly like that covering the omentum on both surfaces, the other half being quite free. Both surfaces of the liver showed large numbers of little greyish flattened nodules varying in size from a split pea downwards. The parietal peritoneum was most extensively affected on the floor of the abdomen, where there was an almost continuous layer of granular greyish tissue. On the sides and roof of the abdominal cavity there were scattered patches of similar tissue.

The left pharyngeal gland contained three caseous tubercles as large as pin's heads. The right popliteal gland contained two similar lesions and the left precrural gland one.

\section{Calf 72.}

Heifer calf. Admitted 17th January I913. The animal's temperature was taken daily from the day of admission until the 27 th January, and it was found to fluctuate between $1008^{\circ}$ and $104^{\circ} 2^{\circ}$. On the 28 th January the animal was tested with tuberculin by the subcutaneous, intracutaneous, and ophthaimic methods. The temperature at the time of injection was $1006^{\circ}$, and the maximum temperature recorded during the following fifteen hours was $104^{\circ} 4^{\circ}$, at the ninth hour. The intracutaneous and ophthalmic tests were entirely negative.

On the 2oth February the animal was inoculated intravenously with Io $\mathrm{mg}$. of culture of avian tubercle bacilli, and the highest temperature recorded during the following fifteen hours was $103^{\circ}$, at the twelfth hour.

On the 2ist June the animal was inoculated subcutaneously on the left side of the neck with $25 \mathrm{mg}$. of culture of bovine tubercle bacilli. The temperature at the day of inoculation was IO3. On the day following the inoculation it was $102^{\circ} 2^{\circ}$, and from that date until the 25 th July it did not exceed $104^{\circ}$. From the 26 th July until the 7 th August the temperature did not exceed $103^{\circ}$ except on the Ist July, when it was $103.6^{\circ}$; 2nd and 3 rd July, when the animal was tested with tuberculin; and 4 th July, when it was IO3. $8^{\circ}$.

At the seat of inoculation on the left side of the neck there formed a swelling which by the 7 th July measured about $1 \frac{1}{2}$ inches in diameter. On the 28 th July it measured about 2 inches in diameter and was rather soft. On the 22 nd August there were two swellings at the seat of inoculation, one measuring $3 \frac{1}{2}$ inches in diameter and the other I inch in diameter. On the I 2 th September the swelling: was opened. The adjacent prescapular gland steadily increased in size, until on the I 5 th August it was about four times the normal, after which it decreased.

The animal was killed on the 5th December I9I3, and the following lesions were found at the post-mortem examination :-

General condition moderate.

At the seat of inoculation on the left side of the neck there was an area of thickened skin measuring about 2 inches in diameter and about $\frac{1}{4}$ inch in thickness. In the centre of this there was found an abscess about the size of a pea containing thick greenish-yellow pus. The left prescapular gland was about twice the normal size, and on section it was found that three- 
-quarters of the gland tissue was replaced by caseous material made up of innumerable little centres packed closely together.

Thoracic Organs, - The pleura covering the base of the right lung was covered with greyish tubercles about the size of a pin's head in the proportion of about a score to the square inch. The costal pleura on each side showed three areas of tuberculous tissue made up of little greyish-pink tubercles about the size of millet. seeds. These areas each measured about 3 inches by $I$ inch, and were situated at the lower extremity of the last three sternal ribs. The posterior mediastinal gland contained a single caseous rubercle about the size of a pin's head.

\section{Calf 73 .}

Heifer calf. Admitted i7th January I913. The animal's temperature was taken twice daily from the day of admission until the 27 th January, and was found to fluctuate between $100.8^{\circ}$ and $1042^{\circ}$.

On the 28 th January it was tested with tuberculin by the. subcutaneous, intracutaneous, and ophthalmic methods. The temperature at the time of injection was $103^{\circ}$, and the highest temperature recorded during the following fifteen hours was $104^{\circ}$, at the twelfth hour. The intracutaneous and ophthalmic tests were entirely negative.

On the 20th February the animal was inoculated intravenously with Io $\mathrm{mg}$. of culture of avian tubercle bacilli, and the highest temperature recorded during the following fifteen hours was $103^{\circ}$, at the ninth hour.

On the 2rst June the animal was inoculated subcutaneously on the left side of the neck with $50 \mathrm{mg}$. of culture of bovine tubercle bacilli. The temperature on the day of inoculation was $103^{\circ}$. From the 22 d June until the 3 oth June the temperature rose above $103^{\circ}$ on three occasions, viz., 23 rd June, $103.8^{\circ} ; 24^{\text {th }}$ June, $103^{\circ} 6^{\circ} ; 26$ th June, $1034^{\circ}$. On the Ist July it was $104^{\circ}$. On the 2 nd and 3 rd July the animal was subjected to a tuberculin test, and from the 4 th July until the 7 th August the temperature did not exceed $102.8^{\circ}$.

At the seat of inoculation there developed a swelling, which slowly increased in size until it measured $2 \frac{1}{2}$ inches in diameter on the 22nd August. Up to the 2 ist July it had been somewhat firm, but it became softened on the 28th July. On the I2th September the swelling was opened. The adjacent prescapular gland slowly increased in size, until on the 22 nd August it was about four times the normal.

The animal was killed on the 5th December I9I3, and the following lesions were found at the post-mortem examination :-

General condition moderate.

At the seat of inoculation on the left side of the neck there was an area of thickened skin measuring 2 inches in diameter and $\frac{1}{4}$ inch in thickness. On section only a brown discoloration was found in its centre. The prescapular gland on the left side was about twice the normal size, and on section was found to contain six caseous centres, each measuring about $\frac{1}{2}$ inch in diameter. On close inspection these caseous centres were found to he composed of a number of smaller centres aggregated together.

Thoracic Organs. - The pleura covering the base of each lung showed about half a dozen little tuft-like outgrowths about as large as barley grains, and the middle third of the lower border of each lung showed a fringe of tuberculous tissue varying in length from a $\frac{1}{4}$ to $\frac{1}{2}$ inch. The costal pleura 
on each side of the chest showed two or three patches, measuring about $\frac{3}{4}$ inch in diameter, composed of aggregations of little greyish nodules about the size of millet seeds. These patches were situated over the lower extremities of the last two ribs. There were similar patches on the adjacent portion of the diaphragm on each side.

\section{Calf 74 .}

Heifer calf. Admitted I 7 th January 19I3. The temperature was. taken twice daily from the day of admission to the 27 th January, and was found to vary from $100^{\circ}$ to $104^{\circ}$.

On the 28th January the animal was tested with tuberculin by the subcutaneous, intracutaneous, and ophthalmic methods. The temperature at the time of injection was $\mathrm{IOI}^{\circ} 4^{\circ}$, and the highest temperature recorded during the following fifteen hours was $104^{\circ} 2^{\circ}$, at the twelfth hour. The intracutaneous and ophthalmic tests gave negative results.

On the 20th February the animal was inoculated intravenously with $10 \mathrm{mg}$. of culture of avian tubercle bacilli, and the highest temperature recorded during the following fifteen hours was $102^{\circ} 6^{\circ}$, at the sixth hour.

On the 2 Ist June the animal was inoculated subcutaneously on the left side of the neck with $25 \mathrm{mg}$. of culture of bovine tubercle bacilli. On the day of inoculation the temperature was $102.8^{\circ}$. On the 22 nd it had fallen to $1016^{\circ}$, and from the 23 rd until the 27 th it varied from $103.2^{\circ}$ to $104.8^{\circ}$. From the 28 th June until the 7 th Angust the temperature did not rise above $102^{\circ} 6^{\circ}$ except on theand and 3 rd July, when the animal was subjected to a tuberculin test, and on the 26 th July, when it was $1034^{\circ}$.

At the seat of inoculation there formed a swelling, which steadily increased in size until on the 22nd August it measured about 3 inches in diameter and was rather soft. On the 12 th September the swelling was opened and its contents evacuated. The adjacent prescapular gland slowly increased in size until it attained a maximum of about three times the normal on the 15th August I9I3.

The animal's temperature had remained normal and its condition fair until the $4^{\text {th }}$ October, after which date the temperature became very variable, oscillating between $102^{\circ}$ and $104^{\circ} 6^{\circ}$, and from this date the animal steadily lost in condition.

The animal was killed on the 22nd October 1913, and the following: lesions were found at the post-mortem examination :-

General condition very poor.

At the seat of inoculation on the left side of the neck there was a circumscribed swelling measuring about $\mathbf{I}$ inch in diameter. On section this was found to be composed of a thick fibrous wall enclosing brownish-yellow contents of a semi-solid consistency. The prescapular gland measured $2 \frac{1}{2}$ inches in length and $\frac{3}{4}$ inch in width, and on section was found to have been almost entirely converted into soft caseous material.

Thoracic Organs. - The lungs were filled with miliary tubercles. The anterior lobes of each lung were still spongy, but the middle lobes and the greater part of the posterior lobes were quite solid. In the solid portions the tubercles were found to have become confluent. The bronchial glands were about twice the normal size and rather pale in colour, but no definitetubercles could be found in them. The largest posterior mediastinal gland 
measured 7 inches in length and $1 \frac{1}{4}$ inches in width, and contained two caseous lesions rather smaller than peas and a collection of about a score of tubercles varying in size from a split pea to a pin's head. Another mediastinal gland was enlarged, and contained a single caseous tubercle about the size of a pea. Two of the glands of the tracheal chain were three or four times the normal size, but no tubercles could be seen in them on section. The right and left prepectoral glands were enlarged to about the same extent, but contained no visible tubercles.

Abdominal Organs.--Five caseous tubercles, varying in size from a millet seed to a pea, were found in the mesenteric glands situated close to the ileo-cæcal valve.

\section{Calf 75 .}

Heifer calf. Admitted 17th January I9I3. The animal's temperature was taken twice daily to the 27 th January, and it was found to fluctuate between $1008^{\circ}$ and $1044^{\circ}$.

On the 28 th January the animal was tested with tuberculin by the subcutaneous, intracutaneous, and ophthalmic methods. The temperature at the time of injection was $1024^{\circ}$, and the highest temperature recorded during the following fifteen hours was $103^{\circ} 6^{\circ}$. The intracutaneous and ophthalmic tests were entirely negative.

On the 2oth February the animal was inoculated intravenously with $20 \mathrm{mg}$. of culture of avian tubercle bacilli, and the highest temperature recorded during the following fifteen hours was $\mathrm{IO}_{4} 2^{\circ}$, at the ninth hour.

On the 2 Ist June the animal was inoculated subcutaneously on the left side of the neck with $50 \mathrm{mg}$. of culture of bovine tubercle bacilli. The temperature on the day of inoculation was $102.2^{\circ}$. From the $23^{\mathrm{rd}}$ to the 27 th June the temperature varied from $103^{\circ} 2^{\circ}$ to $105^{\circ}$, the latter temperature being recorded on the $25^{\text {th }}$ June. From the 28 th June until the 7 th August it did not exceed $103^{\circ}$, except on the ist July, when it was $104^{\circ}$, and on the 2 nd and 3 rd July, when it was tested with tuberculin.

At the seat of inoculation there had formed by the 7 th July a flat swelling measuring 3 inches by 2 inches by $\mathrm{I}$ inch. This slowly increased in size and became slightly softer. The maximum size was reached on the I 5 th August, when it measured 4 inches by 3 inches. On the I2th September the swelling was opened. The adjacent prescapular gland slowly increased in size, and attained a maximum of three times the normal by the $15^{\text {th }}$ August.

The animal was killed on the 5 th December I9I3, and the following lesions were found at the post-mortem examination :-

General condition moderate.

At the seat of inoculation there was a circumscribed swelling measuring about $\mathbf{I}$ inch in diameter. This consisted of a thick fibrous wall enclosing caseous purulent contents which were not gritty. The left prescapular gland was not sensibly enlarged, and on section there were found in it three centres which were about the size of a pea, and contained gritty caseous material.

Thoracic Organs.-The whole of the pleura covering the lungs showed little grey tubercles. These were most numerous and largest over the middle portion of each lung, where they attained the size of barley grains and were almost touching each other. On the anterior and posterior portions of the lung the largest tubercles were about the size of millet seeds, and there were 
about a dozen to the square inch. The costal pleura on each side showed ridges of pinkish-grey tubercles running in the intercostal spaces. In somecases these ridges extended the whole length of the intercostal space, and in others they were broken for about one third of their total length in the middle. . The outer surface of the pericardium was completely covered.with a granular layer of greyish tuberculous tissue, which attained a maximum thickness of about $\frac{7}{16}$ inch.

Abdominal Organs. - The peritoneum covering the abdominal wall was for the most part covered with an almost continuous layer of greyish, granular, tuberculous tissue, which attained a maximum thickness of about $\frac{1}{16}$ inch. On the sides and the roof of the abdominal cavity the areas of tuberculous tissue were more scattered, there being in some places a single nodule only to 2 or 3 square inches. The omentum was almost entirely covered with a layer of tuberculous tissue, with a'maximum thickness of nearly $\frac{1}{4}$ inch. One half of the spleen was almost completely covered on both surfaces with a layer of pinkish-grey granular tissue. The anterior surface of the liver was studded with greyish nodules, varying in size from a millet seed downwards. These were most numerous about the middle of the surface, where they were almost touching each other. On the posterior surface of the organ there was. a similar distribution of tubercles, but the majority of them were smaller.

\section{Calf 82 (Control).}

Heifer calf. Admitted I2th June I9I3. The animal's temperature was taken twice daily from the date of admission until the 17 th June, and was found to fluctuate between $1014^{\circ}$ and $103^{\circ}$. The animal was submitted to the tuberculin test by the subcutaneous, intracutaneous, and ophthalmic methods on the i th June. At the time of injection the temperature was $103^{\circ}$, and the highest temperature recorded during the following fifteen hours was $\mathrm{IO}^{\circ}$, at the twelfth hour. The intracutaneous and ophthalmic tests gave entirely negative results.

On the 2 Ist June the animal was inoculated subcutaneously on the left side of the neck with $25 \mathrm{mg}$. of culture of bovine tubercle bacilli. On the day of inoculation the temperature was $102^{\circ}$. From the $24^{\text {th }} \mathrm{July}$, when it rose to $103.2^{\circ}$, until the 30 th July it varied from $1024^{\circ}$ to $1044^{\circ}$. On the ist July it rose to $106^{\circ}$, and from that date until the $24^{\text {th }} \mathrm{July}$ it did not fall below $104^{\circ}$ except on the $4^{\text {th }}$ July, when it was $103^{\circ} 8^{\circ}$, and on $24^{\text {th }} \mathrm{July}$, when it fell to IOI ${ }^{\circ}$. During this period the temperature was $105^{\circ}$ or over on four occasions.

By the 7 th July there had formed at the seat of inoculation, a rather diffuse swelling measuring 4 by 3 inches and $I$ inch in thickness. This remained about the same size until the 2 Ist July, when it measured 4 inches in diameter and 2 inches in thickness. On that date the swelling was rather firmer than it had been previously. The adjacent prescapular gland attained the size of 5 by $2 \frac{1}{2}$ inches by the 7 th July, and by the 2 Ist it had increased a little in thickness.

The animal was killed on the 25 th July I9I 3 as it was apparently on the point of death, and the following lesions were found at the post-mortem examination :-

General condition very poor.

At the seat of inoculation on the side of the neck there was an oval swelling measuring 4 inches by 2 inches, which on section was found to becom- 
posed of necrotic tissue containing some small cavities from which a watery liquid escaped. The adjacent prescapular gland measured $4 \frac{1}{2}$ by $1 \frac{3}{4}$ inches, and on section it was found to be entirely necrotic.

Thoracic Organs.-Both lungs were solidified with the exception of the upper posterior part of the main lobe. On section they were found to contain innumerable tubercles, the majority of which were about the size of millet seeds. The bronchial glands were about half as large again as normal and were somewhat congested, but no definite tubercles could be found in. them. The posterior mediastinal gland measured 4 inches by $\frac{3}{4}$ inch, and $a$. number of white, opaque tubercles were present in its cortex. The left. prepectoral gland was about twice the normal size, and on section presented an opaque, dull-white appearance, but no tubercles could be detected in it.

Abdominal Organs. - The surface of the liver showed about a score of little grey tubercles, each about the size of a pin's head. Beneath the capsule of the left kidney there were found two tubercles as large as pin's heads.

\section{Calf 83 (Control).}

Heifer calf. Admitted I 2 th June I9I3. The animal's temperature was taken daily from the date of admission until the $17^{\text {th }}$ June, and was found to vary between $1002^{\circ}$ and $103^{\circ}$.

On the 17 th June the animal was tested with tuberculin by the subcutaneous, intracutaneous, and ophthalmic methods. The temperature three hours before the injection of the tuberculin was IO $3: 8^{\circ}$, and at the time of injection it was $1024^{\circ}$. The highest temperature recorded during the following fifteen hours was IO4 $8^{\circ}$, at the sixth hour. The intracutaneous and ophthalmic tests gave entirely negative results.

On the 2 Ist June the animal was inoculated subcutaneously on the left side of the neck with $50 \mathrm{mg}$. of culture of bovine tubercle bacilli. The temperature at the time of inoculation was $1044^{\circ}$, and from this date until the 6 th July it was very variable, fluctuating between $102.2^{\circ}$ and $105^{\circ} 2^{\circ}$. From the 7 th July until the I4th July the temperature remained above $105^{\circ}$, and from I 5 th July until the Ist August it varied from $105^{\circ}$ to $1034^{\circ}$. On the 2nd August it was Ior. $8^{\circ}$.

On the 7 th July there had formed at the seat of inoculation a diffuse swelling measuring 5 by 3 by $1 \frac{1}{2}$ inches in thickness. The adjacent prescapular gland on this date measured 5 inches in length by $2 \frac{1}{2}$ inches in thickness. By the I 3 th July the swelling was somewhat reduced in size, measuring only 3 by 2 inches by $I$ inch. By the 2Ist July the swelling at the seat of inoculation had again increased in size to 5 by 3 by 2 inches, and on that date it was very firm. The prescapular gland showed little or no variation after the 7 th July.

The animal died on the 4th August, and the following lesions. were found at the post-mortem examination:-

General condition very poor.

There was a swelling at the seat of inoculation on the side of the neck measuring 5 inches by 4 inches by 3 inches, which on section was found to consist of a large circumscribed mass of necrotic tissue embedded in the superficial layers of the muscles.

The prescapular gland on the left side when freed from the subcutaneous. 
connective tissue was found to measure 4 by $3 \frac{1}{2}$ by 2 inches, and was almost entirely converted into a pale yellow necrotic material.

Each lung was closely packed with innumerable miliary tubercles, the tubercles being rather more numerous in the anterior half of the lung than in the posterior half. The tubercles varied in size from a pea downwards, and on section were found to have necrotic centres. The bronchial and mediastinal glands were all enlarged to three or four times the normal, and on section were found to be closely packed with small tubercles varying in size from a pea downwards, with necrotic centres.

Heart.-Two tubercles about the size of peas were visible in the wall of the left ventricle. On section these were found to resemble those found in the bronchial glands.

Abdominal Organs.-Beneath the capsule of the liver there could be seen numerous tubercles varying in size from a pin's head to a pea, and numbering about fifteen to the square inch. On section the whole of the parenchyma of the liver was found to contain similar tubercles scattered through it. The portal glands contained six tubercles about the size of peas with small necrotic centres. In the substance of the spleen there were large numbers of tubercles the size of millet seeds. They were more numerous than in the liver. The splenic glands showed six tubercles like those present in the hepatic glands. Each kidney showed six lesions about the size of a pin's head in the cortex after the capsule had been stripped off. No more were found when the kidney was sliced up. With the exception of two, all the mesenteric glands showed tubercles rather smaller than peas, with necrotic centres about the size of a pin's head. In some of the glands there was only one such tubercle, and others contained as many as a dozen. The pharyngeal glands each contained six tubercles exactly like those in the portal glands. Each submaxillary lymphatic gland contained two similar tubercles, and the parotid lymphatic glands each contained four. The glands of the tracheal chain were all enlarged three or four times, and their cortex was beset with necrotic tubercles as large as pins' heads. The left and right iliac glands contained respectively two and four necrotic tubercles rather smaller than peas. The right popliteal gland contained five similar lesions, and each precrural gland contained three. The prepectoral glands were about twice the normal size, and were almost entirely necrotic. 